\title{
Pathogenicity, Virulence, and Vegetative Compatibility Grouping of Verticillium Isolates from Spinach Seed
}

Angela M. Iglesias-Garcia, Maria I. Villarroel-Zeballos, and Chunda Feng, Department of Plant Pathology, University of Arkansas, Fayetteville 72701; Lindsey J. du Toit, Department of Plant Pathology, Washington State University Mount Vernon NWREC, Mount Vernon 98273; and James C. Correll, Department of Plant Pathology, University of Arkansas, Fayetteville

\begin{abstract}
Iglesias-Garcia, A. M., Villarroel-Zeballos, M. I., Feng, C., du Toit, L. J., and Correll, J. C. 2013. Pathogenicity, virulence, and vegetative compatibility grouping of Verticillium isolates from spinach seed. Plant Dis. 97:1457-1469.

In 2005, Verticillium dahliae was first reported to be pathogenic to spinach seed crops in the Pacific Northwest, with symptoms only developing after initiation of the reproductive stage of plant growth, and to be prevalent on commercial spinach seed lots produced in Denmark, The Netherlands, and the United States. In this study, the genetic diversity, pathogenicity, and virulence were examined for a collection of isolates of Verticillium spp. from spinach as well as other hosts (alfalfa, cotton, lettuce, mint, peppermint, potato, radish, and tomato) from various countries and from different vegetative compatibility groups (VCGs). Of a total of 210 isolates of $V$. dahliae obtained from spinach seed produced in Denmark, the Netherlands, New Zealand, or the United States, 128 were assigned to VCG 4B (89\% of 91 U.S. isolates, $86 \%$ of 42 isolates from the Netherlands, $19 \%$ of 43 Denmark isolates, and $8 \%$ of 13 New Zealand isolates), 65 to VCG 2B (92\% of the New Zealand isolates, $79 \%$ of the Denmark isolates, $14 \%$ of the Netherlands isolates, and $9 \%$ of the U.S. isolates), and 3 to VCG 2A (2\% of each of the Denmark and U.S. isolates, and $0 \%$ of the Netherlands and New Zealand isolates); 14 isolates could not be assigned to a VCG. Although little variation in the sequence of the internal transcribed

within each Verticillium sp., the ITS region readily differentiated isolates of the species V. dahliae, V. tricorpus, and Gibellulopsis nigrescens (formerly $V$. nigrescens) obtained from spinach seed. Greenhouse pathogenicity assays on spinach, cotton, lettuce, and tomato plants using isolates of $V$. dahliae ( $n=29$ to 34 isolates), $V$. tricorpus $(n=3)$, G. nigrescens $(n=2)$, and $V$. albo-atrum $(n=1)$ originally obtained from these hosts as well as from alfalfa, mint, peppermint, potato, and radish, revealed a wide range in virulence among the isolates. Isolates of $V$. tricorpus and G. nigrescens recovered from spinach seed and an isolate of $V$. albo-atrum from alfalfa were not pathogenic on spinach. In addition, isolates of $V$. dahliae from mint and peppermint were not pathogenic or only weakly virulent on the hosts evaluated. Although there was a wide range in virulence among the isolates of $V$. dahliae tested, all of the $V$. dahliae isolates caused Verticillium wilt symptoms on spinach, lettuce, tomato, and cotton. None of the isolates of $V$. dahliae showed host specificity. These results indicate that Verticillium and related species associated with spinach seed display substantial variability in virulence and pathogenicity to spinach and other plants but the $V$. dahliae isolates were restricted to three VCGs.
\end{abstract} spacer (ITS) region of ribosomal DNA was observed among isolates
Verticillium dahliae Kleb., a soilborne pathogen, causes Verticillium wilt on more than 200 plant species, including economically important vegetable and field crops (57). The first report of $V$. dahliae on spinach (Spinacia oleracea L.) in the United States was by Snyder and Wilhelm (66) in New York, who reported seed transmission in spinach. Seed transmission in spinach has also been documented in the Netherlands $(78,79)$ and Canada (64). However, it was not until 2005 that $V$. dahliae was first reported to be pathogenic to spinach seed crops in the Pacific Northwest, the main region of spinach seed production in the United States (28). In addition, the prevalence of Verticillium spp. in commercial spinach seed lots was demonstrated in that study. Despite these reports, Verticillium wilt has not been identified as occurring in fresh-market or processing spinach crops in the United States because these crops are harvested before bolting (reproductive stage of growth), and Verticillium wilt symptoms only develop in spinach after initiation of bolting (28). Seed transmission may be important in the epidemiology of Verticillium wilt of a number of crops, including spinach $(26,27)$. Planting a spinach seed crop in an infested field could lead to systemic infection of the plants and, therefore, the production of infected spinach seed (28). Furthermore, planting infested spinach seed could potentially introduce the pathogen to other areas $(6,7,28)$. As a result, efforts have been initiated to treat

Corresponding author: J. C. Correll, E-mail: jcorrell@uark.edu

Accepted for publication 24 April 2013.

http://dx.doi.org/10.1094/PDIS-01-13-0016-RE

(C) 2013 The American Phytopathological Society infested spinach seed lots to reduce the risk of seed transmission $(26,27,29)$.

Although isolates of $V$. dahliae from a given host generally are able to cause symptoms on a range of other plant species $(61,70)$, there are a few exceptions where distinct virulence phenotypes occur, such as cotton (Gossypium hirsutum L.) defoliating and nondefoliating types (32), and tomato (Solanum lycopersicum L.) (10) and lettuce (Lactuca sativa L.) races of V. dahliae (76). In tomato and lettuce, race 1 isolates are controlled by host resistance, whereas race 2 isolates are virulent on race-1-resistant cultivars $(10,76)$. Additionally, some degree of host specialization has been reported among isolates of $V$. dahliae from other hosts, including cocoa (Theobroma cacao L.) (62), tobacco (Nicotiana tabacum L.) (72), mint (Mentha $\times$ gracilis Sole) and peppermint (Mentha $\times$ piperita L.) $(12,25,33)$, bell pepper (Capsicum annuum L.), cabbage (Brassica oleracea L. var. capitata L.), cauliflower (B. oleracea var. botrytis L.), cotton, and eggplant (S. melongena L.) (12). Isolates of V. dahliae, V. tricorpus I. Isaac, and Gibellulopsis nigrescens (Pethybr.) Zare, W. Gams \& Summerb. (formerly V. nigrescens) (85) have also been recovered from seed from spinach germplasm collections and from commercial spinach seed lots (L. J. du Toit, unpublished data; 81,82). Severe symptoms can be caused by $V$. dahliae on several plant species, whereas $V$. tricorpus and $G$. nigrescens are generally reported as weak pathogens or saprotrophs $(9,57)$. There are no published reports of isolates of these species being evaluated for pathogenicity on spinach.

Isolates of $V$. dahliae from diverse hosts have been divided into six main groups based on vegetative compatibility $(11,39)$, with each of vegetative compatibility groups (VCGs) 1, 2, and 4 further divided into two subgroups, $\mathrm{A}$ and $\mathrm{B}$, according to the frequency and vigor of complementation $(41,42,46,63,68)$. Because Verticil- 
lium spp. are apparently asexually reproducing, isolates in the same VCG could be genetically distinct populations with similarity in a number of physiological, ecological, virulence, and host-range traits $(15,46,48,59)$. Thus, genetic diversity of isolates of $V$. dahliae from various hosts has been associated with host preferences and virulence. For instance, isolates belonging to VCG 4A exhibited significantly greater virulence on potato $(S$. tuberosum $\mathrm{L}$.) than isolates of other VCGs $(42,68)$. Additionally, Zeise and von Tiedemann (86) found that the host range of isolates of $V$. dahliae and $V$. longisporum was more related to VCG than to host of origin. Nonetheless, the relevance and suitability of VCG analyses in genetic diversity studies of $V$. dahliae have recently been questioned because of the polyphyletic origin of some of the VCGs, based on analyses of sequences of the intergenic spacer (IGS) region of ribosomal DNA (rDNA) and six other polymorphic sequences (40). A preliminary study on VCGs of five isolates of $V$. dahliae from spinach seed revealed that isolates from spinach belonged to two distinct VCGs, VCGs 2B and 4B (28). However, a comprehensive evaluation of VCGs among isolates of $V$. dahliae from spinach seed has not been completed, nor has the relative virulence of spinach seed isolates been investigated.

In addition to VCGs, genetic diversity of V. dahliae isolates has been studied by analysis of DNA based on nuclear ribosomal RNA genes and various molecular markers $(16,17,49,53)$. The internal transcribed spacer (ITS) region of rDNA has been used frequently in phylogenetic studies of Verticillium spp. $(13,56,61)$. However, sequences of the ITS rDNA and mitochondrial genes have failed to differentiate isolates within a Verticillium spp. $(4,61)$. Furthermore, analyses of the association between genetic diversity and characteristics of isolates of $V$. dahliae have often been contradictory. Whereas the relationships among isolates based on molecular markers have been associated with variables such as geographic origin of strains (55), original host $(55)$, pathotype $(45,58)$, and VCG (22), other genetic studies found no correlation between characteristics of isolates of $V$. dahliae and molecular data $(5,12,23)$. Even though several studies have been completed on genetic diversity within the genus Verticillium, isolates of Verticillium from crops such as spinach have not been characterized extensively. Management of Verticillium wilt in general is difficult due to the broad host range of the pathogen and the persistence of microsclerotia in soils $(43,57,76)$. Additionally, economic, environmental, and regulatory constraints may hinder the application of effective soil fumigants $(5,43)$. Because Verticillium wilt of spinach is a relatively newly recognized disease, little is known about the genetic diversity of Verticillium spp. found on spinach seed and the pathogenicity to spinach and related crops of Verticillium spp. recovered from spinach seed. Thus, the objectives of this study were to characterize VCG diversity, pathogenicity, and virulence of a collection of Verticillium and related species recovered from spinach seed as well as several other plant hosts. This may help with development of effective management practices for Verticillium wilt in spinach seed crops and other crops susceptible to these fungi.

\section{Materials and Methods}

Isolates of Verticillium spp. A collection of 261 isolates of $V$. dahliae and other Verticillium spp. from spinach and eight other plant species was used in this study. Monoconidial isolates were recovered from each culture prior to storage. Isolates were stored at $-20^{\circ} \mathrm{C}$ on desiccated filter paper as described by Correll et al. (21). The isolates were selected from a larger collection of isolates to represent isolates of VCGs 2A, 2B, and 4B (following VCG determination as described below) and different countries of origin. The collection included 255 isolates of $V$. dahliae, of which 212 were recovered from spinach seed lots produced in the United States, Denmark, the Netherlands, and New Zealand (28); 3 isolates were recovered from cotton, 22 from lettuce, 3 from mint, 1 from peppermint, 8 from potato, 3 from radish (Raphanus sativus L.), and 3 from tomato. Additionally, three isolates of $V$. tricorpus (two from spinach seed from the United States Department of Agriculture
[USDA] spinach germplasm collection and one from peppermint), two isolates of $G$. nigrescens recovered from spinach seed, and an isolate of V. albo-atrum Reinke \& Berthold from alfalfa (Medicago sativa L.) were included in this study.

A subset of 40 representative isolates of Verticillium and related species was examined microscopically $(\times 40$ to $\times 100$ magnification) for the presence or absence of resting structures and verticillate conidiophores to determine the conformity with known morphological standards for species of Verticillium (57). This core group included 34 isolates of $V$. dahliae from VCGs $2 \mathrm{~A}, 2 \mathrm{~B}$, and $4 \mathrm{~B}$, of which 15 were recovered from spinach seed lots produced in the United States, Denmark, and the Netherlands (28); 3 isolates from cotton; 5 from lettuce; 2 from mint; 1 from peppermint; 4 from potato; 1 from radish; and 3 from tomato (Table 1). Additionally, two isolates of $G$. nigrescens recovered from spinach seed, three isolates of $V$. tricorpus (two from spinach seed from the USDA spinach germplasm collection and one from peppermint), and an isolate of $V$. albo-atrum from alfalfa were included (Table 1). Isolates were grown on potato dextrose agar (PDA; Difco) and on NP-10 agar, a semiselective medium for Verticillium spp. (67), at $22^{\circ} \mathrm{C}$ for 14 to 21 days.

VCG analysis. A total of 250 isolates of $V$. dahliae was examined for VCG diversity. To generate chlorate-resistant mutants, mycelial plugs of each isolate were placed on $5 \%$ water agar chlorate medium (WAC) (20 g of agar, $0.2 \mathrm{~g}$ of glucose, and $50 \mathrm{~g}$ of $\mathrm{KClO}_{3}$ per liter) (46), and the resultant chlorate-resistant sectors were transferred to a minimal agar medium (MM) (30 g of sucrose, $1 \mathrm{~g}$ of $\mathrm{KH}_{2} \mathrm{PO}_{4}, 0.5 \mathrm{~g}$ of $\mathrm{MgSO}_{4}, 0.5 \mathrm{~g}$ of $\mathrm{KCl}, 0.01 \mathrm{~g}$ of $\mathrm{FeSO}_{4}, 0.2$ $\mathrm{ml}$ of trace elements, $20 \mathrm{~g}$ of agar, and $2 \mathrm{~g}$ of $\mathrm{NaNO}_{3}$ per liter) to confirm that they were nitrate nonutilizing (nit) mutants. VCG tests were conducted as described previously $(20,41)$, with an incubation period of 10 to 21 days. Reference VCG testers of $V$. dahliae belonging to VCG 1 (T9 and V44), VCG 2A (PH and WM), VCG 2B (115, S92, VD1/13, and VD5/16), VCG 3 (70-21 and PCW), VCG 4A (BB and P-103), and VCG 4B (MT, S39, VD2/22, and VD4/36) were used in complementation tests (69). The nit mutants that formed heterokaryons, observed as wild-type growth where the two nit mutants came in contact, were assigned to the same VCG.

Amplification of the ITS rDNA region, and phylogenetic analysis. The core group of 40 isolates of Verticillium representing different hosts, countries of origin, and VCGs was examined after polymerase chain reaction (PCR) amplification of the ITS1-5.8SITS2 region of rDNA using the ITS primers ITS1 (5'-TCCGTA GGTGAACCTGCGG-3') and ITS4 (5'-TCCTCCGCTTATTGA TATGC-3') (83). Total DNA was extracted from the isolates following a standard procedure (19). PCR amplifications were each performed in a $100-\mu l$ volume containing sterilized distilled water, $20 \mathrm{ng}$ of fungal DNA, $0.2 \mu \mathrm{M}$ primer, $2.0 \mathrm{mM} \mathrm{MgCl}_{2}, 100 \mu \mathrm{M}$ dNTP, $1 \times$ Taq polymerase buffer, and 2.0 units of DNA Taq polymerase. For amplification, a thermal cycler (Eppendorf) was programmed for $5 \mathrm{~min}$ at $94^{\circ} \mathrm{C} ; 35$ cycles of $30 \mathrm{~s}$ at $94^{\circ} \mathrm{C}, 30 \mathrm{~s}$ at $55^{\circ} \mathrm{C}$, and $2 \mathrm{~min}$ at $72^{\circ} \mathrm{C}$; and a final extension period at $72^{\circ} \mathrm{C}$ for 5 min. The amplified products were separated electrophoretically in $1.0 \%$ agarose gels in $0.5 \times$ Tris-acetate-EDTA (TAE) buffer. PCR products were then purified using a QIAquick PCR purification Kit (Qiagen) following the manufacturer's instructions. Purified DNA was sequenced at the University of Arkansas DNA Resource Center (Fayetteville). Sequences were visualized in Chromas (Technelysium) and aligned using Clustal W (47). Phylogenetic relationships among the sequences were calculated by neighborjoining using MEGA 4 software (71). Bootstrap values were calculated with 1,000 resampling replicates.

Pathogenicity and virulence analyses. Pathogenicity and virulence of the core group of 40 isolates of Verticillium were determined using the inbred spinach line AC1, 'DP 161' cotton, 'Bradley' tomato, and lettuce line plant introduction (PI) 251246. AC1 is a smooth-leaf, strongly female line selected for partial resistance to Fusarium wilt that is susceptible to V. dahliae (28). PI 251246 is an early-flowering lettuce line previously used to evaluate Verticillium wilt symptoms in growth-chamber tests (44). 
Seed were sown in 200-cell seedling plug trays (Hummert Int.) and maintained for approximately 3 weeks on benches in a greenhouse or in a growth chamber with $12 \mathrm{~h}$ of supplemental light by day and $23^{\circ} \mathrm{C}$ average temperature. Temperatures in the greenhouse were 6.7 to $21.8^{\circ} \mathrm{C}$ in winter and 19.9 to $37.7^{\circ} \mathrm{C}$ in summer. Plants were fertilized once per week in the seedling trays and after transplanting with Miracle-Gro (Stern's Miracle-Gro) at $1.5 \mathrm{~g} / \mathrm{liter}$ of water.

To prepare inoculum for the greenhouse experiments, isolates of Verticillium were grown on PDA plates at room temperature for 2 weeks. Conidia were collected by washing the agar surface using cold, sterilized, deionized water. Conidial concentrations were quantified with a hemacytometer and adjusted to $1 \times 10^{7}$ conidia $/ \mathrm{ml}$. A standard root-dip inoculation protocol was used in the pathogenicity assays, similar to that described by du Toit et al. (28). The length of the root plug of each seedling was trimmed one-quarter with sterile scissors. Plants were then inoculated with each isolate by dipping the roots in $50 \mathrm{ml}$ of conidial suspension per seedling for at least $1 \mathrm{~h}$; then, each inoculated seedling was planted into Sunshine LC1 potting mix in a $15-\mathrm{cm}$-diameter pot. Water was used similarly for treating the noninoculated control plants, and care was taken to sterilize gloves between isolates to avoid cross-contamination. For all the pathogenicity assays, four pots (replications) were used per treatment, with three plants per pot. The pots were arranged in a randomized complete block design on greenhouse benches. Plants were monitored daily for symptom development and to determine when to induce bolting (conversion from vegetative to reproductive growth) by increasing the duration of the greenhouse supplemental lighting, as described below.

Plants were monitored once per week for incidence and severity of Verticillium wilt from 9 to 28 days after inoculation. For the spinach inoculation experiments, disease severity was rated using a scale of 0 to $6(28,81,82)$, in which $0=$ no symptoms, $1=>0$ to $10 \%$ of the plant showing chlorosis or necrosis, $2=>10$ to $25 \%$ chlorosis or necrosis, $3=>25$ to $50 \%$ chlorosis or necrosis, $4=$ $>50$ to $75 \%$ chlorosis or necrosis, $5=>75$ to $<100 \%$ chlorosis or necrosis, and $6=$ dead plant. The midpoints of each range $(0.0,5.0$, $17.5,37.5,62.5,87.5$, and $100.0 \%$ ) were used for statistical analysis. For the inoculation experiments on cotton, each plant was rated on a 0 -to- 3 scale, where $0=$ no symptoms, $1=$ mild chlorosis and necrosis ( $>0$ to $<50 \%$ chlorosis or necrosis), $2=$ severe chlorosis and necrosis ( $>50 \%$ to $<100 \%$ chlorosis or necrosis), and $3=$ dead plant (100\% chlorosis and necrosis). The midpoints of each category range $(0.0,25.0,75.0$, and $100.0 \%)$ were used for statistical analysis. For the assays on lettuce and tomato, disease severity was expressed as the percentage of leaves symptomatic (chlorotic or necrotic) per plant.

Disease scoring was performed for individual plants and then averaged per pot (experimental unit). For the analysis of variance (ANOVA), means for the last day of scoring were compared. ANOVA was conducted using JMP Software (SAS Institute Inc.), with $95 \%$ confidence intervals for detection of statistically significant differences among treatments. Comparisons of isolates were

Table 1. Core isolates of Verticillium species from spinach and non-spinach hosts used to evaluate variation in internal transcribed spacer (ITS) rDNA sequence, virulence, and pathogenicity on spinach and other plant hosts

\begin{tabular}{|c|c|c|c|c|}
\hline Species $^{\text {a }}$ & Host & Isolate code & Origin & $\mathbf{V C G}^{\mathbf{b}}$ \\
\hline Verticillium dahliae & Spinach & WSU 107 & Denmark & $2 \mathrm{~B}$ \\
\hline$V$. dahliae & Spinach & WSU 210 & Denmark & $2 \mathrm{~B}$ \\
\hline V. dahliae & Spinach & WSU 523 & The Netherlands & $2 \mathrm{~B}$ \\
\hline V. dahliae & Spinach & WSU 541 & The Netherlands & $2 \mathrm{~B}$ \\
\hline V. dahliae & Spinach & WSU 268 & United States & $2 \mathrm{~B}$ \\
\hline V. dahliae & Spinach & WSU 384 & United States & $2 \mathrm{~B}$ \\
\hline V. dahliae & Spinach & VD1 & United States & $2 \mathrm{~B}$ \\
\hline V. dahliae & Spinach & $\mathrm{JD} 4 \mathrm{ss} 2$ & United States & $2 \mathrm{~B}$ \\
\hline V. dahliae & Spinach & WSU 311 & Denmark & 4B \\
\hline V. dahliae & Spinach & WSU 359 & Denmark & $4 B$ \\
\hline V. dahliae & Spinach & WSU 511 & The Netherlands & $4 B$ \\
\hline V. dahliae & Spinach & WSU 509 & The Netherlands & $4 B$ \\
\hline V. dahliae & Spinach & WSU 139 & United States & $4 \mathrm{~B}$ \\
\hline V. dahliae & Spinach & WSU 49 & United States & $4 B$ \\
\hline V. dahliae & Spinach & VD4 & United States & $4 B$ \\
\hline V. dahliae & Cotton & Gh1011 & United States & $2 \mathrm{~A}$ \\
\hline V. dahliae & Cotton & Gh1018 & United States & $2 \mathrm{~A}$ \\
\hline V. dahliae & Cotton & CS1 & United States & $2 B$ \\
\hline V. dahliae & Lettuce & Ls847 & United States & $2 \mathrm{~A}$ \\
\hline V. dahliae & Lettuce & Ls636 & United States & $2 \mathrm{~A}$ \\
\hline V. dahliae & Lettuce & Ls822 & United States & $2 \mathrm{~A}$ \\
\hline V. dahliae & Lettuce & Ls842 & United States & $2 \mathrm{~A}$ \\
\hline V. dahliae & Lettuce & Ls 17 & United States & $2 \mathrm{~B}$ \\
\hline V. dahliae & Mint & LD4 & United States & $2 B$ \\
\hline V. dahliae & Mint & LD2 & United States & $2 B$ \\
\hline V. dahliae & Peppermint & LD1 & United States & $2 B$ \\
\hline V. dahliae & Potato & P19 & United States & $2 \mathrm{~B}$ \\
\hline V. dahliae & Potato & JD1 & United States & $2 \mathrm{~B}$ \\
\hline V. dahliae & Potato & W140 & United States & $4 B$ \\
\hline V. dahliae & Potato & JD2 & United States & $4 B$ \\
\hline V. dahliae & Radish & RV1 & United States & $4 B$ \\
\hline V. dahliae & Tomato & Le1103 & United States & $4 B$ \\
\hline V. dahliae & Tomato & Le1112 & United States & $4 \mathrm{~B}$ \\
\hline V. dahliae & Tomato & Le1101 & United States & $4 \mathrm{~B}$ \\
\hline V. tricorpus & Spinach & USDA 11 & United States & n.d. \\
\hline$V$. tricorpus & Spinach & USDA 29 & United States & n.d. \\
\hline V.tricorpus & Peppermint & VB1aM & United States & n.d. \\
\hline V. albo-atrum & Alfalfa & LD9 & United States & n.d. \\
\hline Gibellulopsis nigrescens & Spinach & LD10 & United States & n.d. \\
\hline G. nigrescens & Spinach & USDA 95 & United States & n.d. \\
\hline
\end{tabular}

\footnotetext{
a Species based on morphological evaluation and sequences of the ITS region of ribosomal DNA. G. nigrescens $=$ Verticillium nigrescens (85).
}

b VCG = vegetative compatibility group verified as described in the main text $(20,41)$; n.d. = not determined. 
made using Fisher's least significant difference (LSD) tests $(P \leq$ $0.05)$. Correlation analyses of disease severity ratings among isolates used in the various tests were calculated using JMP Software with $95 \%$ confidence intervals.

In each experiment, two petiole pieces per experimental unit were cut from symptomatic and asymptomatic plants, surface-disinfested by immersing the tissue in $0.5 \% \mathrm{NaOCl}$ for $1 \mathrm{~min}$, and plated on water agar to test for the presence or absence of Verticillium spp. Each petiole piece was examined with a microscope $(\times 10$ to $\times 100$ magnification) approximately 5 days after plating for the presence of Verticillium microsclerotia or conidiophores. Plant height and dry weight per plant were also evaluated as a complement to disease evaluations for the cotton and tomato inoculation tests. The dry weight of plants was determined by cutting each plant approximately $1 \mathrm{~cm}$ below the soil line, placing the plant in a paper bag, and drying the plant for $96 \mathrm{~h}$ in a forced-draft air oven set at $55^{\circ} \mathrm{C}$. Plant height and dry weight data were analyzed by ANOVA and LSD comparison of means, and the correlation coefficients of plant growth parameters and disease severity were calculated using JMP. Plant height and dry weight data were not collected for the inoculated spinach plants based on prior experience with Verticillium wilt ratings of spinach (82).

All inoculation tests were conducted at least twice. Plants in each test were evaluated multiple times but disease ratings were analyzed statistically for the last day of evaluation. The disease rating selected for statistical analysis for each host was based on when disease severity was at a maximum for at least one of the plants in the test. For the first spinach test, which was performed during the summer, seedlings were kept in a growth chamber and, after inoculation, were exposed to long photoperiods in a greenhouse 11 days after inoculation, which induced bolting. For the second spinach test, plants were induced to bolt 15 days after inoculation by increasing the duration of supplemental lighting to 24 $\mathrm{h}$ for 3 days. For both spinach tests, disease severity was assessed 27 days after inoculation. For the first and second cotton inoculation tests, severity of symptoms was assessed 24 and 22 days after inoculation, respectively. For tomato, disease ratings were assessed 27 days after inoculation for both tests. To induce bolting of lettuce, the duration of the greenhouse supplemental lighting was increased to $16 \mathrm{~h}$ for 1 day after inoculation in the first test, which was completed in the winter, and plants were observed to bolt 3 days after inoculation. For the second lettuce test, performed dur- ing the summer, seedlings were kept in a growth chamber and, after inoculation, were exposed to long photoperiods in a greenhouse, which induced bolting 3 days after inoculation. Severity of symptoms was assessed 28 days after inoculation for both lettuce tests.

\section{Results}

Morphological analysis. Microscopic and cultural examination of the core set of 40 isolates of Verticillium spp. evaluated in this study revealed characteristics consistent with those of $V$. alboatrum, V. dahliae, V. tricorpus, and G. nigrescens $(24,57,85)$ (Table 1). The morphological examinations were completed based on the more broad taxonomic classification of Verticillium and did not include the more recently proposed taxa whereby the genus was divided into 10 species (35).

VCG analysis. VCG analysis of 250 isolates of $V$. dahliae indicated that isolates belonged to VCGs $2 \mathrm{~A}, 2 \mathrm{~B}$, or 4B. Of 210 isolates of $V$. dahliae obtained from spinach seed, 128 isolates belonged to VCG $4 \mathrm{~B}, 65$ isolates to VCG $2 \mathrm{~B}$, and 3 isolates to VCG $2 \mathrm{~A}$ (Table 2). For the remaining 14 isolates, nit mutants could not be recovered despite several attempts. Of the 128 isolates that belonged to VCG 4B, $81(63.3 \%)$ originated from spinach seed lots produced in the United States, $8(6.2 \%)$ from seed produced in Denmark, $36(28.1 \%)$ from seed grown in the Netherlands, 1 $(0.8 \%)$ from seed produced in New Zealand, and 2 (1.6\%) from seed of unknown origin (Table 2). Of the 65 isolates in VCG 2B, 8 $(12.3 \%)$ originated from spinach seed lots produced in the United States, while $34(52.3 \%)$ isolates originated from Denmark, 6 $(9.2 \%)$ from the Netherlands, $12(18.5 \%)$ from seed produced in New Zealand, and $5(7.7 \%)$ from seed of unknown origin (Table 2 ). Of the three spinach isolates that belonged to VCG $2 \mathrm{~A}$, two $(66.7 \%)$ originated from seed produced in the United States and one (33.3\%) from seed produced in Denmark. Interestingly, of the 91 isolates of $V$. dahliae obtained from U.S. spinach seed crops, only $8(8.8 \%)$ belonged to VCG $2 \mathrm{~B}$, whereas $81(89.0 \%)$ belonged to VCG $4 \mathrm{~B}$, and the remaining $2(2.2 \%)$ belonged to VCG $2 \mathrm{~A}$. A similar ratio was observed for the 42 isolates obtained from spinach seed grown in the Netherlands; that is, six $(14.3 \%)$ belonged to VCG 2B whereas $36(85.7 \%)$ belonged to VCG 4B. In contrast, of the 43 isolates from spinach seed crops produced in Denmark, 34 (79.1\%) belonged to VCG $2 \mathrm{~B}$, only $8(18.6 \%)$ belonged to VCG 4B, and $1(2.3 \%)$ belonged to VCG2A.

Table 2. Summary of vegetative compatibility group (VCG) analysis of 235 isolates of Verticillium dahliae

\begin{tabular}{|c|c|c|c|c|}
\hline \multirow[b]{2}{*}{$\mathbf{V C G}^{\mathbf{a}}$} & \multirow[b]{2}{*}{ Number of isolates ${ }^{b}$} & \multicolumn{2}{|c|}{ Origin of isolates } & \multirow[b]{2}{*}{ Total } \\
\hline & & Host crop & Country, state & \\
\hline \multirow[t]{8}{*}{$4 \mathrm{~B}$} & 81 & Spinach & United States, Washington & \\
\hline & 8 & Spinach & Denmark & \\
\hline & 36 & Spinach & The Netherlands & -128 \\
\hline & 1 & Spinach & New Zealand & \\
\hline & 2 & Spinach & Unknown & \\
\hline & 4 & Potato & United States, Washington & 4 \\
\hline & 3 & Radish & United States, Oregon & 3 \\
\hline & 3 & Tomato & United States, California & 3 \\
\hline \multirow[t]{9}{*}{$2 B$} & 8 & Spinach & United States, Washington & \\
\hline & 34 & Spinach & Denmark & \\
\hline & 6 & Spinach & The Netherlands & -65 \\
\hline & 12 & Spinach & New Zealand & \\
\hline & 5 & Spinach & Unknown & \\
\hline & 1 & Potato & United States, Washington & 1 \\
\hline & 1 & Peppermint & United States, Texas & 1 \\
\hline & 3 & Mint & United States, Texas & 3 \\
\hline & 1 & Lettuce & United States, California & 1 \\
\hline \multirow[t]{4}{*}{$2 \mathrm{~A}$} & 2 & Spinach & United States, Washington & -3 \\
\hline & 1 & Spinach & Denmark & -3 \\
\hline & 21 & Lettuce & United States, California & 21 \\
\hline & 2 & Cotton & United States, California & 2 \\
\hline
\end{tabular}

\footnotetext{
a VCG verified as described in the main text $(20,41)$.
}

${ }^{\mathrm{b}}$ Number of isolates that belong to VCG 4B, VCG 2B, or VCG 2A, organized by host and geographic region of origin.

${ }^{c}$ Total number of isolates by host crop that belong to VCG 4B, VCG $2 \mathrm{~B}$, and VCG $2 \mathrm{~A}$. 
Of the 22 isolates of $V$. dahliae from lettuce, 21 belonged to VCG $2 \mathrm{~A}$ and only 1 belonged to VCG $2 \mathrm{~B}$. Four of the six isolates of $V$. dahliae from potato plants belonged to VCG $4 \mathrm{~B}$, one to VCG $2 \mathrm{~B}$, and one (isolate LD6) failed to form a heterokaryon with the testers. All three radish isolates of $V$. dahliae (RV1, RV2, and RV3) and the three tomato isolates of $V$. dahliae (Le1101, Le1102, and Le1103) belonged to VCG 4B. The peppermint isolate and three mint isolates of $V$. dahliae belonged to VCG 2B. The two cotton isolates of $V$. dahliae (Gh1011 and Gh1018) belonged to VCG 2A (Table 2).
Comparison of DNA sequence variation in the ITS rDNA region of Verticillium. The ITS primers ITS1 and ITS4 amplified a 400- to 500-bp DNA fragment from all 40 isolates in the core collection. A 429-bp sequence of the ITS1-5.8S-ITS2 region of the isolates was used to generate a neighbor-joining tree that discriminated the isolates into two major clusters, representing the genera Verticillium and Gibellulopsis (Fig. 1). Based on alignment of the sequences, isolates of $V$. dahliae, $V$. tricorpus, $V$. albo-atrum, and $G$. nigrescens were discriminated, and the sequence identity was

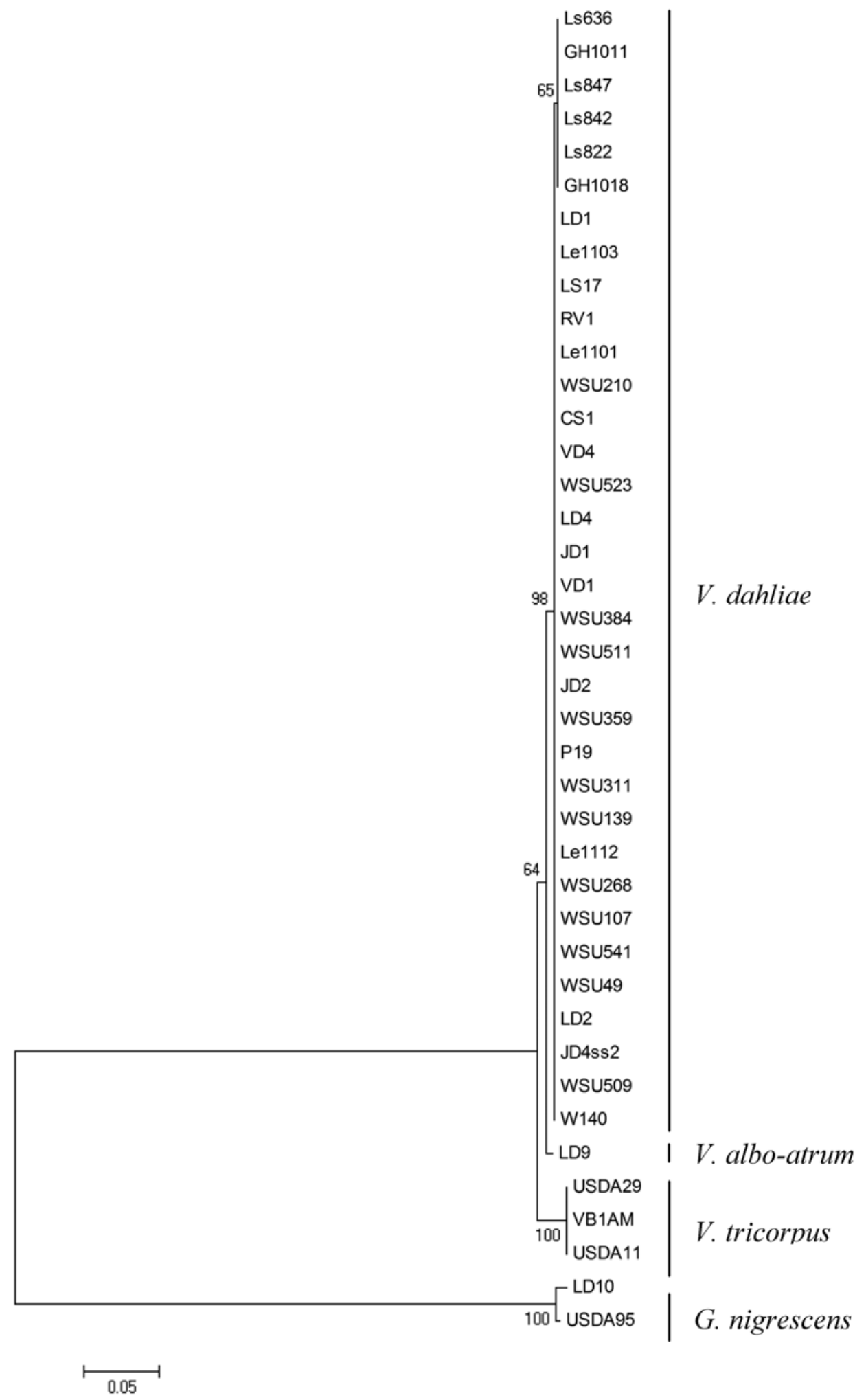

Fig. 1. Neighbor-joining tree derived from sequences of the internal transcribed spacer (ITS)1-5.8s-ITS2 ribosomal DNA region of isolates of Verticillium dahliae, V. alboatrum, V. tricorpus, and Gibellulopsis nigrescens. Bootstrap values (1,000 replicates) are indicated adjacent to the nodes. 
confirmed by comparison with ITS sequences in GenBank (data not shown).

No variation occurred in this ITS region among 28 of the 34 isolates of $V$. dahliae. However, six isolates of $V$. dahliae in VCG 2A, representing four isolates from lettuce (Ls636, Ls822, Ls842, and Ls847) and two from cotton (Gh1011 and Gh1018), had a single nucleotide polymorphism (SNP) at base pair 296 in the ITS region. Thus, the isolates of $V$. dahliae clustered into two groups, one including isolates of VCG 2B and 4B and the other containing the six isolates with an SNP which belonged to VCG 2A. There was no ITS sequence variation among the three isolates of $V$. tricorpus examined. However, minor variation in ITS sequences was observed among the two isolates of $G$. nigrescens examined (4-bp differences).

Pathogenicity and virulence analyses. Analyses of data from pathogenicity experiments with isolates of Verticillium tested on spinach, cotton, tomato, and lettuce indicated differential pathogenicity among isolates of the species of Verticillium obtained from spinach and non-spinach hosts. Although the isolates of $V$. dahliae exhibited a broad host range, there were virulence differences among isolates of $V$. dahliae from the hosts examined. All inoculation tests were conducted at least twice and results on the same crop were similar, with no significant effect of experiment on results for any individual crop. Thus, for each of the plant species evaluated, results of just one of the repeat experiments are presented below.

Inoculation of spinach. Distinct symptoms of Verticillium wilt developed between 12 and 27 days after inoculation of spinach plants with the 40 isolates of Verticillium. There was a wide range in disease severity caused by the isolates. Of the 29 isolates of $V$. dahliae examined, 27 caused symptoms of Verticillium wilt on spinach, with significant differences in incidence and severity of Verticillium wilt caused by the isolates $(P<0.0001$ at $\alpha=0.05)$ (Fig. 2). Disease incidence and severity were 25.0 to 100.0 and 2.3 to $99.9 \%$, respectively. Isolates of $V$. dahliae from spinach and in VCG 2B caused disease severity ratings of 32.5 to $86.5 \%$, with a mean \pm standard error of $74.5 \pm 5.9 \%$, and isolates in VCG 4B caused severity ratings of 42.5 to $78.1 \%$, with a mean of $64.1 \pm$ $6.1 \%$ (Fig. 2). Isolates of $V$. dahliae from spinach, lettuce, potato, tomato, and radish were consistently pathogenic on spinach line AC1. Isolates Ls822 and Ls847 of $V$. dahliae from lettuce ranked consistently among the most virulent isolates examined. Isolates of $V$. dahliae from peppermint and mint (LD1 and LD4, respectively) as well as isolates of $V$. tricorpus, $V$. albo-atrum, and G. nigrescens were nonpathogenic on spinach under these conditions. V. dahliae was recovered from petiole sections (100\% incidence) sampled from symptomatic plants inoculated with isolates of $V$. dahliae. In contrast, V. tricorpus, V. albo-atrum, and G. nigrescens were not recovered from petioles or stem sections of plants inoculated with isolates of these species, all of which remained asymptomatic. In general, more severe ratings were observed in the first experiment than in the second experiment. In the second experiment, isolates of $V$. dahliae in VCG 2B from spinach caused disease severity ratings of 23.0 to $72.5 \%$, with a mean of $46.3 \pm 6.3 \%$, and isolates in VCG 4B from spinach caused disease severity of 20.6 to $59.8 \%$, with a mean of $38.7 \pm 5.1 \%$. However, highly significant correlations existed between disease severity ratings for the two experiments $(R=0.67 ; P<0.0001)$.

Inoculation of cotton. All isolates of $V$. dahliae caused Verticillium wilt symptoms on cotton DP 161 , with a final Verticillium wilt incidence of 8.3 to $100 \%$ and severity of 2.1 to $66.7 \%(P<$

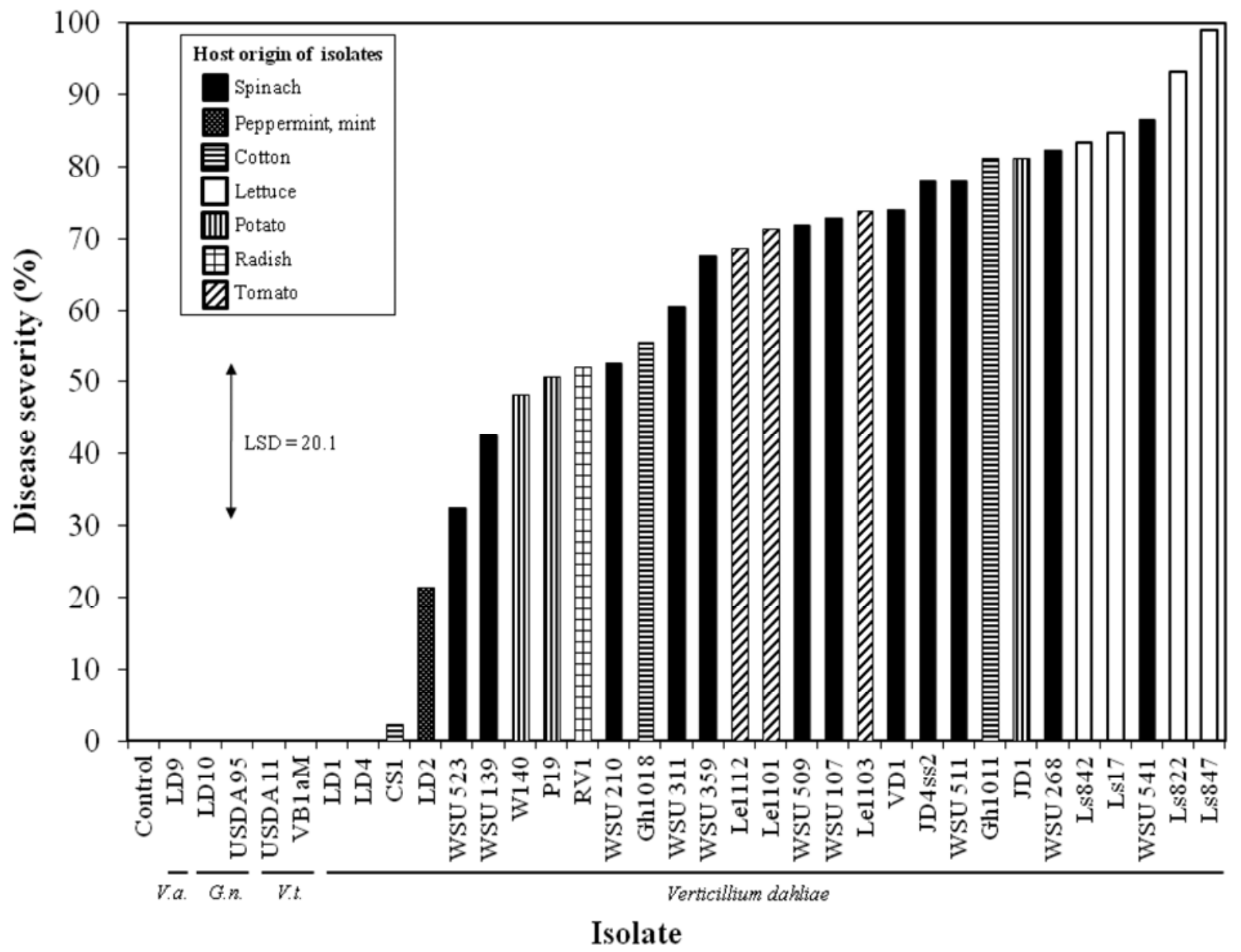

Fig. 2. Effect of isolates of Verticillium spp. from spinach and non-spinach hosts on severity of Verticillium wilt on spinach inbred line AC1. Mean disease severity rating was converted to percentage (midpoint) values and averaged for three plants/pot and four pots/treatment. Disease severity ratings of 0 were not included in statistical analyses. $\mathrm{LSD}=$ least significant difference at $P<0.05$. V.t. $=$ Verticillium tricorpus, V.a. $=$ V. albo-atrum, G.n. $=$ Gibellulopsis nigrescens. 
0.0001 at $\alpha=0.05$ ) (Fig. 3). Isolates of $V$. dahliae in VCG 2B that were originally obtained from spinach caused disease severity on cotton of 25.0 to $52.1 \%$, with a mean of $39.9 \pm 4.0 \%$, and isolates in VCG 4B from spinach caused severity ratings on cotton of 16.7 to $50.0 \%$, with a mean of $31.0 \pm 4.1 \%$. The isolates of $V$. dahliae in VCG $2 \mathrm{~B}$ and the two isolates in VCG 2A from cotton caused symptoms of 20.8 to $66.7 \%$ in severity and $>94 \%$ incidence (Fig. 3 ). In both inoculation tests on cotton, isolates of $V$. dahliae from cotton, lettuce, potato, and tomato, as well as one isolate from radish, were pathogenic on cotton DP 161 . Isolates of $V$. dahliae from peppermint and mint were weakly virulent and isolates from spinach and lettuce were virulent to highly virulent on cotton, with the lettuce isolate of Ls847 consistently ranking among the most virulent. All isolates of $V$. tricorpus, G. nigrescens, and $V$. alboatrum were nonpathogenic on DP 161 cotton.

There was significant variation in dry weight of cotton plants inoculated with the different isolates of Verticillium, ranging from 0.4 to $1.4 \mathrm{~g} /$ plant $(P<0.0001$ at $\alpha=0.05)$ (Fig. 4). There also was a significant reduction in plant dry weight relative to that of the noninoculated cotton plants for all Verticillium isolates examined except for two isolates of $V$. tricorpus, USDA11 and VB1aM, originally obtained from spinach and peppermint, respectively. $V$. tricorpus isolate USDA29 and $G$. nigrescens isolates LD9 and LD10 caused very mild reductions in weight of cotton plants (Fig. 4). The five isolates that caused the greatest reduction in cotton plant weight were from spinach (WSU 523, WSU 359, and JD4ss2) and lettuce (Ls847 and Ls822). A highly significant negative correlation between disease severity and plant dry weight was calculated $(R=-0.62 ; P<0.0001)$. There was a significant difference in the height of the cotton plants inoculated with the different isolates of Verticillium ( $P<0.0001$ at $\alpha=0.05$ ) (Fig. 5), with a significant reduction in plant height caused by 27 of the 33 isolates of $V$. dahliae examined (Fig. 5). There was also a highly significant negative correlation between plant height and disease severity ratings $(R=-0.76 ; P<0.0001)$. $V$. dahliae was recovered from $100 \%$ of the petiole sections sampled from symptomatic cotton plants that had been inoculated with $V$. dahliae. In contrast, $V$. tricorpus, V. albo-atrum, and G. nigrescens were not recovered from petiole sections of the plants inoculated with isolates of these species, with all of these plants remaining asymptomatic.

Inoculation of tomato. Of 30 isolates of $V$. dahliae inoculated on Bradley tomato, 22 caused Verticillium wilt symptoms, with significant differences in disease severity and incidence among the isolates $(P<0.0001$ at $\alpha=0.05$ for both variables). Disease incidence and severity were 8.3 to 100 and 1.4 to $100.0 \%$, respectively (Fig. 6). Only 8 of the 13 isolates of $V$. dahliae from spinach caused Verticillium wilt symptoms on tomato, with a range in severity of 1.4 to $10.4 \%$. The three isolates of $V$. dahliae from tomato (Le1101, Le1103, and Le1112) caused symptoms on Bradley of 65.0 to $100.0 \%$ severity, with $100 \%$ disease incidence. These three isolates of $V$. dahliae from tomato, as well as three isolates from lettuce (Ls847, Ls842, and Ls822), one isolate from cotton (Gh1011), and one from potato (P19), caused more severe symptoms of Verticillium wilt on Bradley than the other isolates of $V$. dahliae (Fig. 6). Tomato plant height also was affected significantly differently among isolates $(P<0.0001$ at $\alpha=0.05)$ (Fig. 7), with a significant reduction in plant height caused by 9 of the 30 isolates of $V$. dahliae examined. There was a highly significant negative correlation between the height of tomato plants and disease severity rating $(R=-0.76 ; P<0.0001)$. $V$. dahliae was recov-

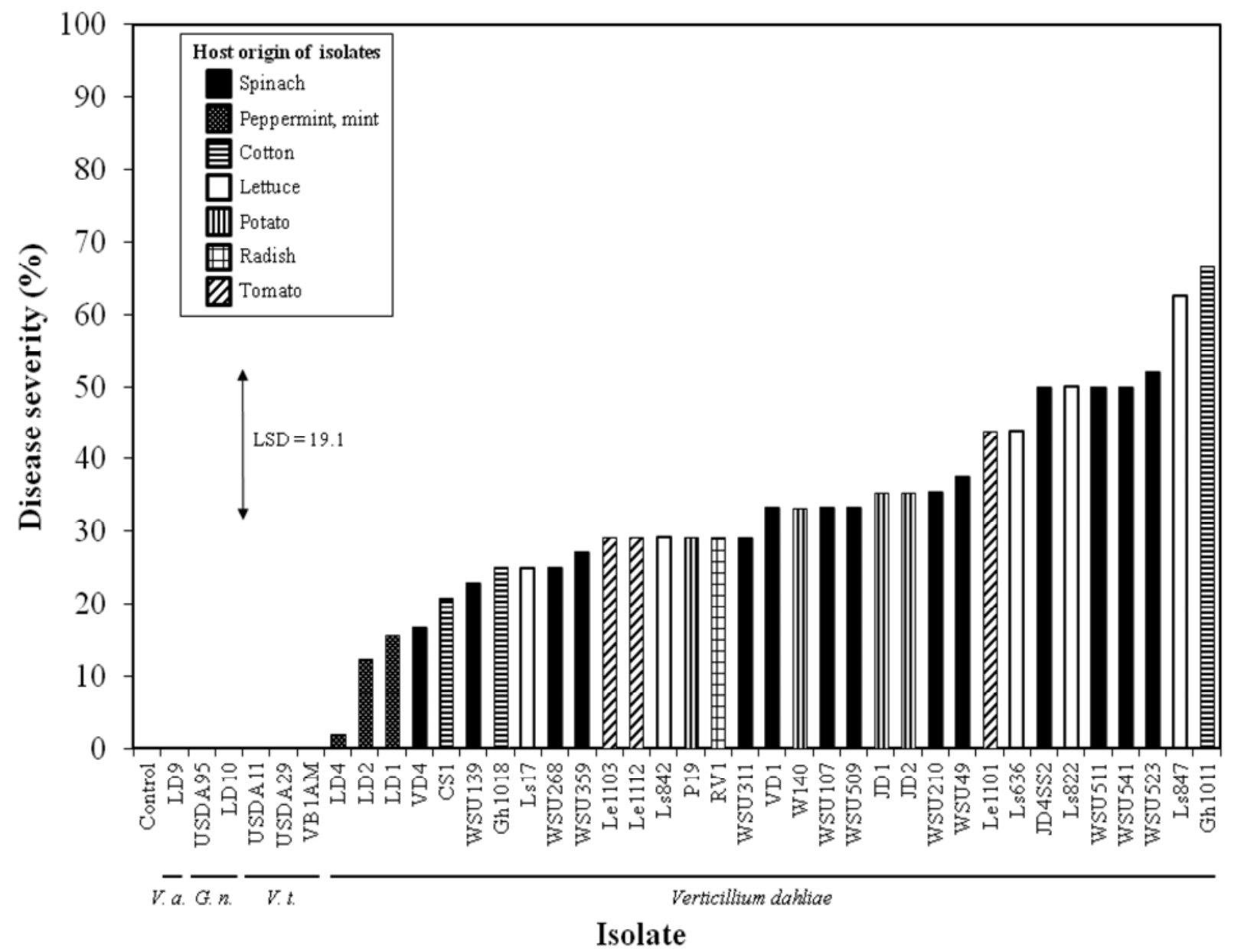

Fig. 3. Effect of isolates of Verticillium spp. from spinach and non-spinach hosts on severity of Verticillium wilt on the cotton 'DP 161'. Mean disease severity rating was converted to percentage (midpoint) values and averaged for three plants/pot and four pots/treatment. Disease severity ratings of 0 were not included in statistical analyses. $\mathrm{LSD}=$ least significant difference at $P<0.05$. V.t. $=$ Verticillium tricorpus, V.a. $=$ V. albo-atrum, G.n. $=$ Gibellulopsis nigrescens. 
ered from $100 \%$ of the petiole sections sampled from symptomatic plants inoculated with $V$. dahliae. In contrast, $V$. tricorpus and $G$. nigrescens were not recovered from petiole sections of plants inoculated with isolates of these species, and all of these plants remained asymptomatic. Consistent results were observed in the repeat inoculation test.

In both inoculation tests on tomato, isolates of $V$. dahliae from tomato and lettuce were virulent to highly virulent on Bradley. There was variation in severity of symptoms among isolates of $V$. dahliae ranging from nonpathogenic to highly virulent. In general, isolates of $V$. dahliae from spinach, peppermint, and mint were nonpathogenic to weakly virulent on tomato, whereas isolates from lettuce, tomato, and a cotton isolate were moderately to highly virulent. Although tomato plants were smaller in the second test, in both experiments, the same nine isolates of $V$. dahliae reduced plant height significantly relative to the height of noninoculated control plants (data not shown).

Inoculation of lettuce. Of 31 isolates of $V$. dahliae inoculated onto lettuce plants, 30 were pathogenic, with significant differences in disease severity and incidence observed among the isolates $(P<0.0001$ at $\alpha=0.05)$. Disease incidence and severity were 41.7 to 100.0 and 2.8 to $58.9 \%$, respectively (Fig. 8). Isolates of $V$. dahliae in VCG 2B from spinach caused disease severity ratings on lettuce line P1 251246 of 8.9 to $26.7 \%$, with a mean of $17.7 \pm$ $2.2 \%$, and isolates in VCG 4B from spinach caused ratings of 13.9 to $27.8 \%$, with a mean of $19.5 \pm 2.1 \%$. An isolate of $V$. dahliae from cotton (CS1) was nonpathogenic on lettuce, as were the isolates of $V$. tricorpus and $G$. nigrescens. Isolates of $V$. dahliae VCG 2A from lettuce caused symptoms on lettuce line P1 251246 ranging in severity from 31.7 to $58.9 \%$. $V$. dahliae was recovered only from petiole sections (55\% incidence) sampled from symptomatic plants inoculated with isolates of $V$. dahliae. In contrast, $V$. tricorpus and G. nigrescens were not recovered from petiole sections of the plants inoculated with isolates of these species, which remained asymptomatic. Overall, in both repeats of the lettuce inoculation experiment, isolates of $V$. dahliae from lettuce, potato, tomato, and radish were pathogenic. There was variation in severity of symptoms among isolates, ranging from weakly virulent to moderately to highly virulent for isolates of $V$. dahliae from spinach and cotton, and from weakly virulent to moderately virulent for isolates from mint and peppermint.

\section{Discussion}

$V$. dahliae was reported on commercial spinach seed lots in 2005, and has since been recognized as a concern for spinach seed production in the European Union and the United States (28). Furthermore, although $V$. dahliae does not appear to cause symptoms in vegetative, fresh-market, or processing spinach crops, the incidence of the pathogen on commercially produced spinach seed lots is a major concern due to the potential of introducing the pathogen when planting infested spinach seed into noninfested fields in which other Verticillium wilt-susceptible crops are grown (28). For instance, recent outbreaks of Verticillium wilt in lettuce have been associated, in part, with the presence of $V$. dahliae on spinach seed lots planted in rotation with lettuce crops in the Salinas Valley of California, as well as other susceptible plant species rotated with lettuce (e.g., strawberry [Fragaria $\times$ ananassa], pepper, and artichoke [Cynara scolymus]), based on molecular analyses of populations of the pathogen using microsatellite markers and population analyses $(6,7)$. This has highlighted the need to investigate the pathogenicity and virulence on spinach and alternative crops of Verticillium isolates obtained from spinach seed. Such studies may be important for developing effective management strategies for Verticillium wilt, including appropriate crop rotation schemes. Results of this study help elucidate the degree of host specificity, diversity in virulence, and genetic diversity of isolates of Verticillium from spinach seed as well as isolates from crops that might be grown in rotation with spinach.

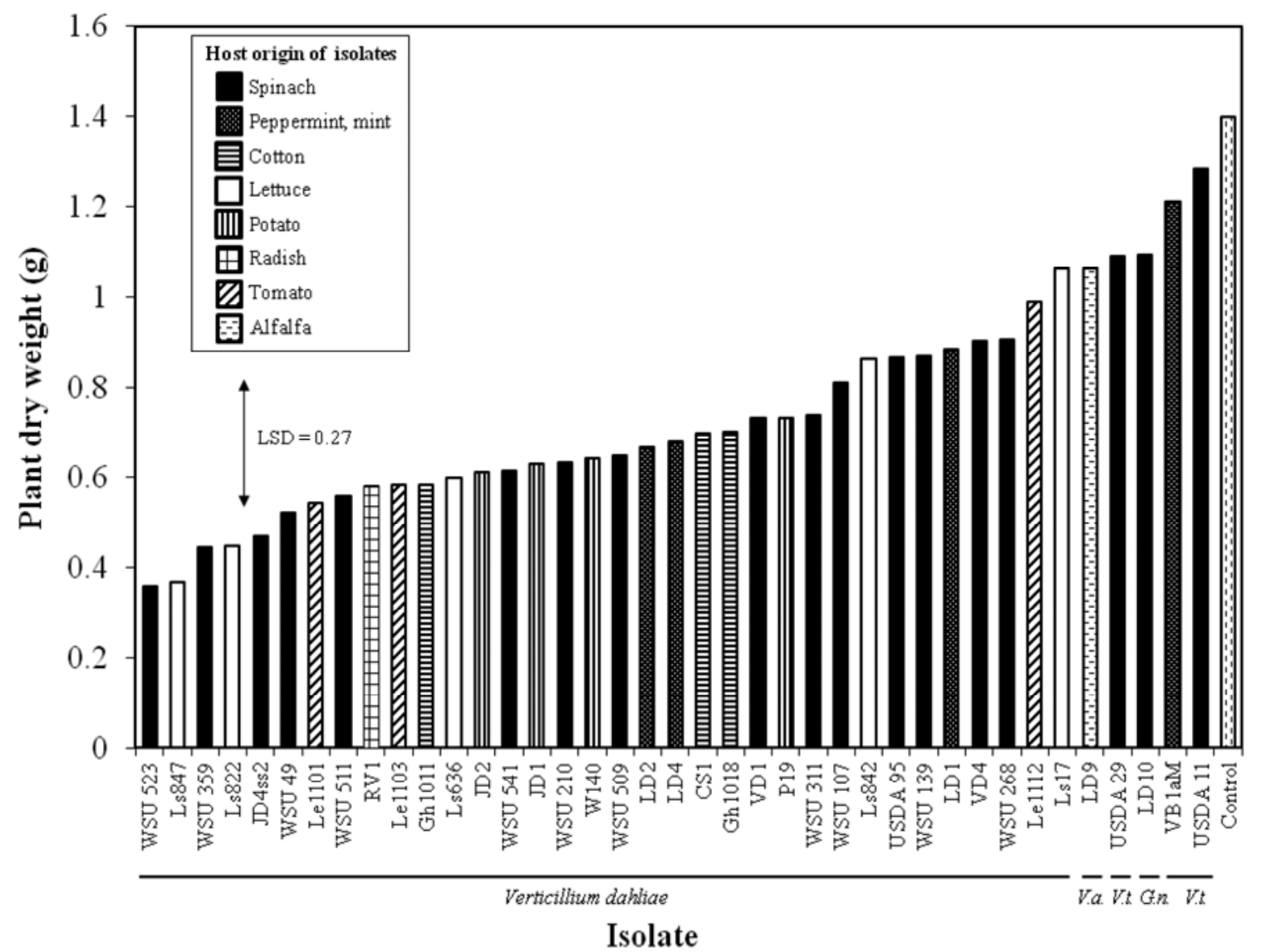

Fig. 4. Effect of isolates of Verticillium spp. from spinach and non-spinach hosts on plant dry weight of the cotton 'DP 161'. Mean plant dry weight (g) of four pots/isolate with three plants/pot. LSD = least significant difference at $P<0.05$. V.t. $=$ Verticillium tricorpus, V.a. $=$ V. albo-atrum, G.n. $=$ Gibellulopsis nigrescens. 
In previous studies, $>700$ isolates of Verticillium were recovered from spinach seed produced in Denmark, the Netherlands, the United States, and New Zealand (28; L. J. du Toit et al., unpublished data). From this diverse collection, the predominant species recovered was $V$. dahliae. However, additional taxa, including V. tricorpus and G. nigrescens, were recovered from these spinach seed lots as well as from seed of PI lines from the USDA germplasm repository (L. J. du Toit et al., unpublished data;

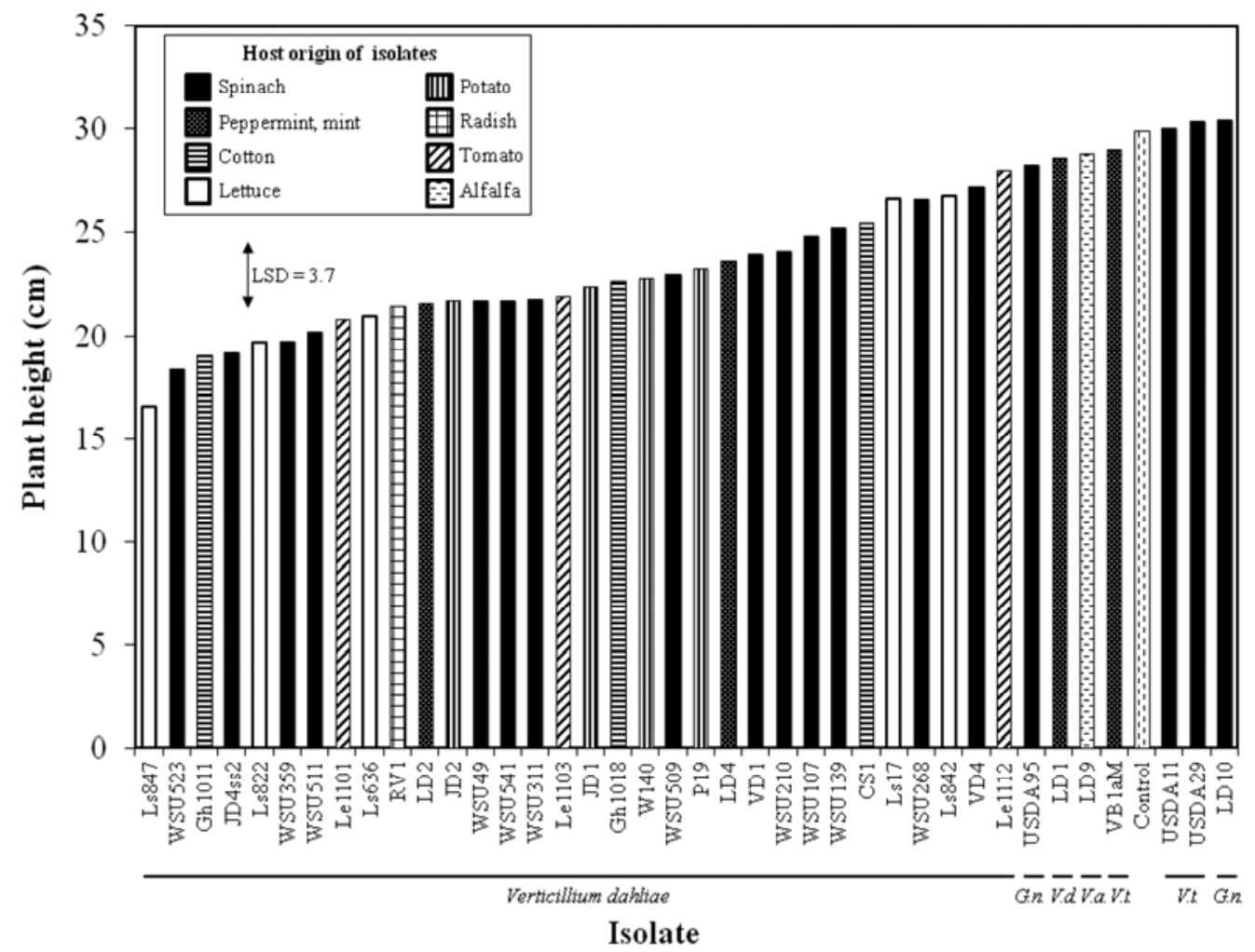

Fig. 5. Effect of isolates of Verticillium spp. from spinach and non-spinach hosts on plant height of the cotton 'DP 161'. Mean of plant height (cm) of four pots/isolate with three plants/pot. LSD = least significant difference at $P<0.05$. V.t. $=$ Verticillium tricorpus, V.a. $=$ V. albo-atrum, G.n. $=$ Gibellulopsis nigrescens.

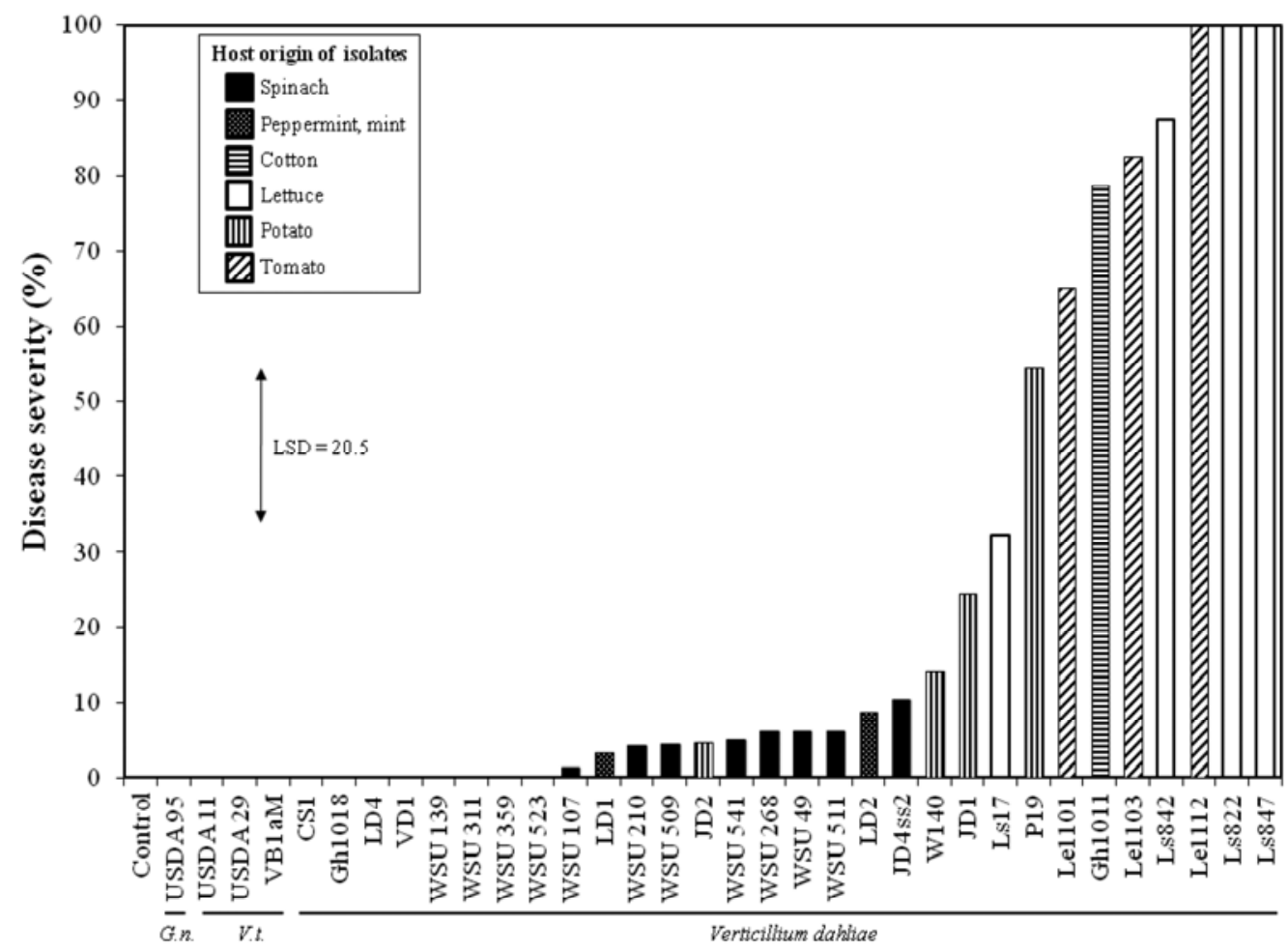

Isolate

Fig. 6. Effect of isolates of Verticillium spp. from spinach and non-spinach hosts on Verticillium wilt severity on tomato 'Bradley'. Mean disease severity rating was converted to a percentage (midpoint) and averaged for three plants/pot and four pots/treatment. Disease severity ratings of 0.0 were not included in statistical analyses. LSD $=$ least significant difference at $P<0.05$. V.t. $=$ Verticillium tricorpus, G.n. $=$ Gibellulopsis nigrescens. 
$30,81,82$ ). Examination of a subset of 210 isolates of $V$. dahliae from this collection of isolates demonstrated that the majority of spinach isolates belonged to one of two VCGs, VCG 2B or VCG $4 \mathrm{~B}$, and a very small proportion belonged to VCG $2 \mathrm{~A}$. The major- ity of isolates from Denmark were grouped in VCG 2B, whereas the majority of isolates from the United States and the Netherlands were in VCG 4B. Differences in VCGs may be associated with crop rotation practices in regions where spinach seed is produced,

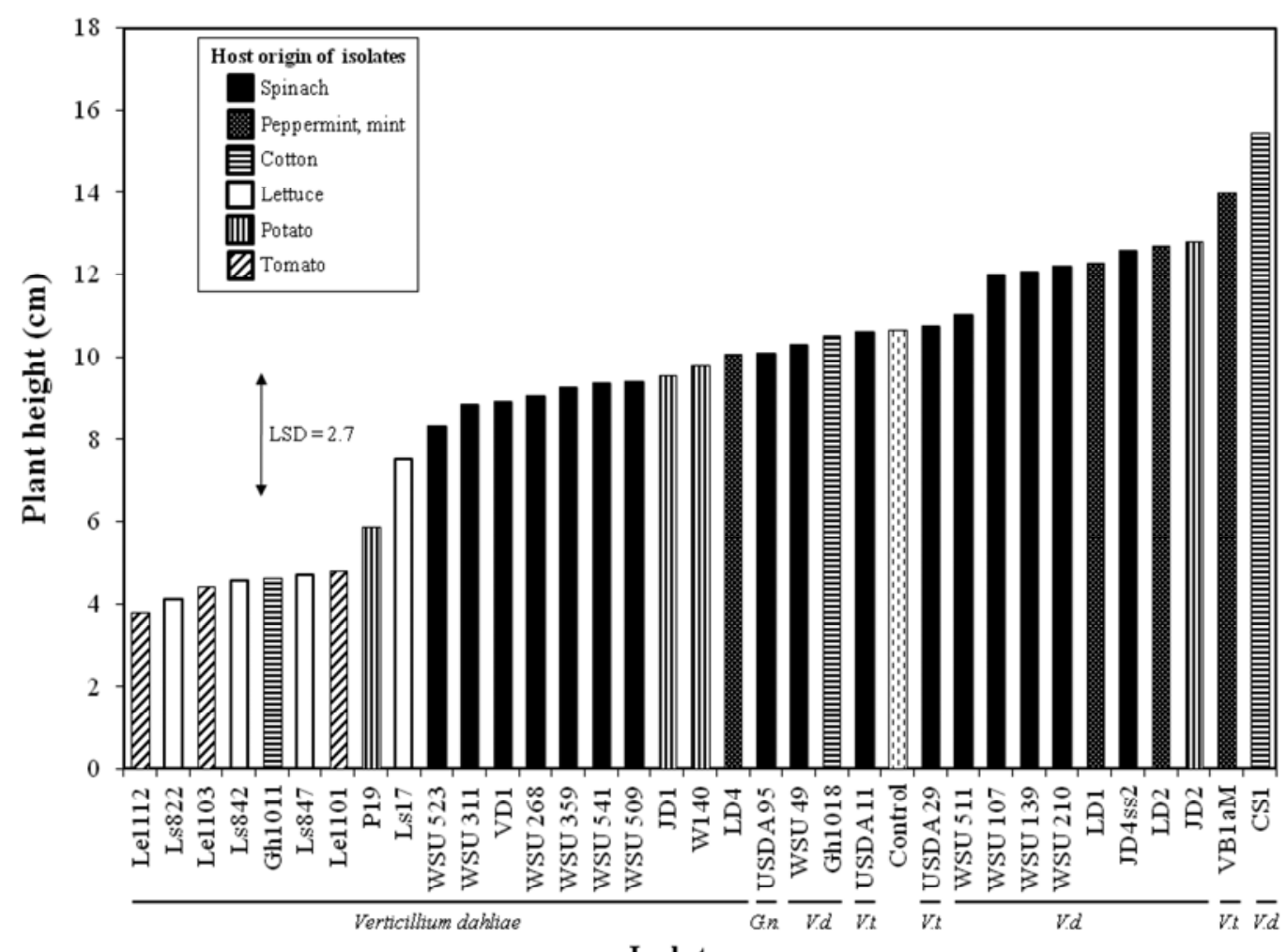

Isolate

Fig. 7. Effect of isolates of Verticillium spp. from spinach and non-spinach hosts on height of 'Bradley' tomato plants. Each data point is the mean plant height (cm) in four replicate pots/isolate with three plants/pot. LSD = least significant difference at $P<0.05$. V.t. $=$ Verticillium tricorpus, G.n. $=$ Gibellulopsis nigrescens.

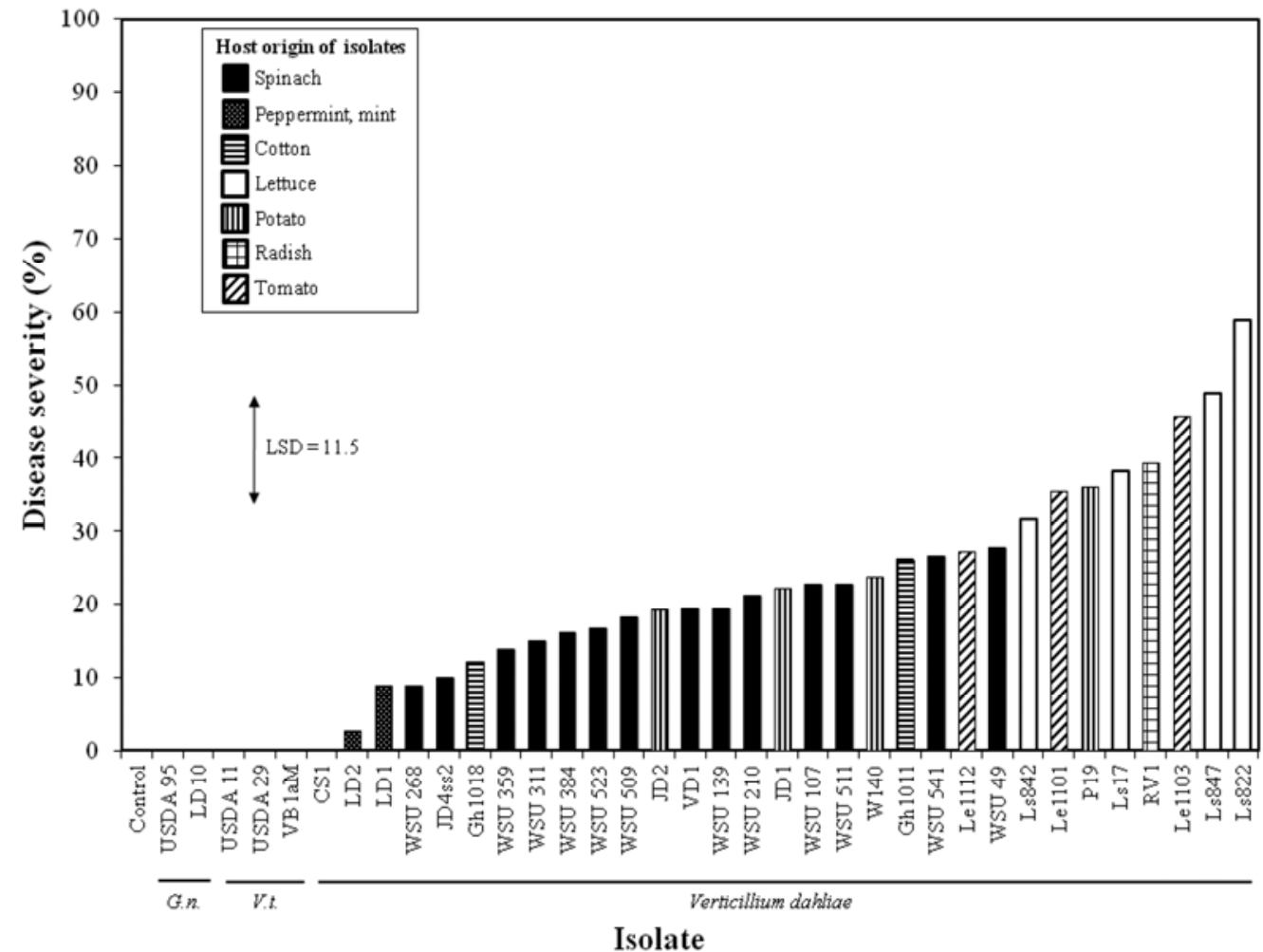

Fig. 8. Effect of isolates of Verticillium spp. from spinach and non-spinach hosts on Verticillium wilt severity of the lettuce line PI 251246. Mean disease severity rating was converted to a percentage (midpoint) and averaged for three plants/pot and four pots/treatment. Disease severity ratings of 0 were not included in statistical analyses. LSD = least significant difference at $P<0.05$. V.t. $=$ Verticillium tricorpus, G.n. $=$ Gibellulopsis nigrescens . 
as well as susceptibility of these crops to isolates of $V$. dahliae in VCGs $2 \mathrm{~A}, 2 \mathrm{~B}$, and $4 \mathrm{~B}$. In the United States, spinach seed is produced almost solely in the maritime Pacific Northwest because of the favorable climatic conditions necessary for producing highquality spinach seed. In this maritime region of the United States, spinach seed crops are commonly grown in rotation with potato, with a significant increase in potato acreage in western Washington over the last 20 years $(2,50)$. This may have contributed to increasing populations of $V$. dahliae isolates of VCG 4, because isolates in this VCG are predominant among those pathogenic on potato $(42,68)$. In Denmark, spinach seed crops are most commonly rotated with cereals and grass seed, which are not susceptible to $V$. dahliae, and, to a minor degree, with crops such as sugar beet (Beta vulgaris) (73). Similarly, in the Netherlands, spinach seed crops are commonly rotated with potato crops. However, the association between cropping history and populations of $V$. dahliae in specific VCGs needs further examination.

In this study, a subset of 40 Verticillium isolates from different VCGs, host plants, and geographic origins was evaluated for VCG diversity, sequence variation in the ITS region of rDNA (83), and pathogenicity on spinach, cotton, tomato, and lettuce. Sequences of the ITS rDNA distinguished and confirmed that taxa associated with spinach seed include $V$. dahliae, V. tricorpus, and $G$. nigrescens. However, little to no variation was observed among isolates within each species for the ITS sequences. Because of morphological similarities among the Verticillium spp. recovered from spinach seed, identification of these species should be completed carefully, particularly when the incidence of $V$. dahliae in seed lots may have economic implications. For example, spinach seed exported to Mexico currently must meet a phytosanitary certification requirement of $<10 \%$ contamination by $V$. dahliae (1), whereas there are no regulations for the presence of other species of Verticillium on spinach seed.

Although caution should be exercised to avoid extrapolating from limited collections of isolates, the lack of differentiation among isolates of $V$. dahliae from different hosts examined in this study, and the tendency for isolates to cluster within a limited number of VCGs in the phylogenetic analysis, supports studies by Attallah et al. (6,7). After analyzing 22 microsatellite markers and a collection of $243 \mathrm{~V}$. dahliae isolates from different plants hosts, Attallah et al. (6) found evidence of significant gene flow among isolates from host plants they evaluated (artichoke, lettuce, pepper, spinach, strawberry, and some weed species). They suggested that recombination within $V$. dahliae populations might explain recent outbreaks of Verticillium wilt in crops that formerly were not affected by Verticillium, specifically lettuce, by the introduction of novel pathogen genotypes to major areas of production of these "immune" plant species.

Lack of a significant correlation between molecular or genetic diversity and virulence characteristics of $V$. dahliae was observed in this study, as documented by other authors $(8,11,12,23,52,54)$. Furthermore, the incongruence among VCG characterization, virulence, and genetic characteristics of the isolates would confirm recent concerns about the suitability and relevance of vegetative compatibility as a genetic marker in diversity studies $(5,40)$. Therefore, although the majority of lettuce isolates used in this study belonged to VCG $2 \mathrm{~A}$, a VCG different from the predominant groups detected in spinach isolates, no conclusions can be drawn, and the need remains for further evaluation of populations of $V$. dahliae to assess the potential origin and impact of isolates of the pathogen that might affect both spinach seed and lettuce production.

Among the fungal taxa recovered from spinach seed and examined for pathogenicity on spinach, tomato, cotton, and lettuce, isolates of $V$. tricorpus and $G$. nigrescens were nonpathogenic on each of these hosts. Furthermore, none of the isolates could be recovered from the petioles of plants inoculated with these isolates. Although $V$. tricorpus and G. nigrescens have generally been reported as weak pathogens on some plant species $(31,38,51,60$, $65,80,84)$ or as plant pathogens, especially under conducive environmental conditions $(34,36-38,74,75)$, pathogenicity of isolates of these species was not observed in this study. Nonpathogenic isolates of $V$. tricorpus on Chinese cabbage, cotton, eggplant, green pepper, larkspur, parsley, snapdragon, soybean, tobacco, and tomato $(31,34,65)$ have been documented, as well as nonpathogenic isolates of $G$. nigrescens on cantaloupe, eggplant, peppermint, and tomato (65). Differential pathogenicity among isolates of Verticillium may reflect the distinct genetic background of some of the isolates used in previous studies, which recently have led to taxonomic revisions of the genus $(35,85)$. In this study, isolates of $V$. tricorpus and G. nigrescens were recovered originally from spinach seed; therefore, factors leading to colonization of spinach seed by these isolates remain to be determined. Vascular colonization was not evident in these studies; therefore, one hypothesis is the possibility of aerial infection of spinach flowers and developing seed, similar to what has been observed by $V$. dahliae on flowering lettuce plants (77).

Inoculation of 40 Verticillium and related species onto spinach, cotton, tomato, and lettuce indicated differential pathogenicity and virulence among the isolates. None of the isolates of $V$. dahliae examined was pathogenic specifically to a single host; however, the isolates did exhibit different degrees of virulence on the host plants evaluated. Correspondingly, previous reports have characterized $V$. dahliae as a host-adapted pathogen that, despite the capacity to infect a wide range of hosts, is more virulent on certain crops $(25,70)$. All isolates of $V$. dahliae from spinach, cotton, tomato, and lettuce evaluated in this study were pathogenic on the host plants from which they were originally recovered. In general, isolates of $V$. dahliae from spinach were more virulent on cotton and lettuce than on tomato, whereas isolates of $V$. dahliae from lettuce, potato, and tomato were pathogenic on spinach, cotton, tomato, and lettuce; and isolates from peppermint and mint were nonpathogenic or very weakly virulent on those crops. The lack of virulence of mint and peppermint isolates might be related to the pronounced host specialization previously reported for isolates from these plant species $(12,25,33)$. These isolates had previously been confirmed as pathogenic on mint and peppermint cultivars by D. Johnson at Washington State University (personal communication). Isolates of $V$. dahliae from cotton that were inoculated on spinach, lettuce, and tomato ranged from nonpathogenic to pathogenic, with a wide range in virulence among the pathogenic isolates. These data support the results of previous studies in which the virulence of isolates from cotton on cotton were quite variable (3). Although a single isolate of $V$. albo-atrum from alfalfa was included in the inoculation experiments, the results indicated differential pathogenicity of this isolate, as documented previously $(12,18)$. However, additional isolates of $V$. albo-atrum should be evaluated on various plant hosts for more definitive conclusions.

Verticillium spp. were recovered only from symptomatic petiole pieces sampled from plants inoculated with isolates of $V$. dahliae, which is consistent with previous reports of isolations of Verticillium from various plant hosts (12). However, in some other studies, $V$. dahliae was recovered from asymptomatic roots (14). Isolation from roots of inoculated plants was not assessed in this study. Nevertheless, asymptomatic infection of spinach by $V$. dahliae has been indicated by du Toit et al. (28), because seed-to-seed transmission occurred on some spinach plants without definitive symptoms evident, possibly confounded by Verticillium wilt symptoms resembling natural senescence of spinach plants after flowering and pollination. In the absence of wilt symptoms, measurement of plant growth (dry weight and plant height) can be used in conjunction with the assessment of severity of Verticillium wilt for some crops (e.g. spinach, cotton, and tomato), as demonstrated in this study. The fact that severity of symptoms on spinach has been correlated significantly with reduced plant weight suggests that $V$. dahliae can have a significant effect on plant growth even in the absence of symptoms, as sometimes is the case in spinach seed crops (L. J. du Toit and J. C. Correll, unpublished data).

Results of the pathogenicity experiments confirmed that $\mathrm{V}$. dahliae isolates recovered from spinach seed are pathogenic on spin- 
ach, as previously reported $(28,66)$. However, a continuum of virulence was found among the spinach seed isolates, from weakly to highly virulent. This has been observed on others hosts such as cotton (3), lettuce (76), and potato (42). This range of virulence among isolates affects assessment of the potential impact of a population of the pathogen on a spinach seed crop. The relationship between inoculum density and disease severity might differ among fields or among regions within a field, and could be associated with the relative incidence of different isolates in specific locations.

Isolates of $V$. dahliae from lettuce, potato, radish, and tomato were as virulent on spinach as isolates recovered from spinach. The susceptibility of spinach to isolates of $V$. dahliae known to be pathogenic on other species of vegetables is highly significant because some of these crops are grown in the same areas of production as spinach (e.g., potato is commonly grown in rotation with spinach seed crops in the Pacific Northwest United States [28]). The current hypothesis that isolates from spinach seed may be associated, at least in part, with outbreaks of Verticillium wilt on lettuce in the Salinas and Pajaro Valleys of California, two major areas of vegetable production $(6,7)$, is supported by results of this study, because isolates of $V$. dahliae from spinach were pathogenic on lettuce and vice versa. However, some of the most virulent isolates on spinach were lettuce isolates in VCG 2A. It is not known what proportion of isolates causing Verticillium wilt of lettuce in California belongs to VCG 2A but isolates of VCG 2A were not prevalent among isolates from spinach seed evaluated in this study. VCG analysis may not provide a full assessment of genetic diversity (40) and, because of the lack of significant correlation between genetic markers and virulence phenotypes of isolates of Verticillium (8), there is a need for further genetic analyses of populations of $V$. dahliae recovered from spinach and lettuce.

Identification of rotation crops that might influence infection of spinach by $V$. dahliae, and vice versa, as well as a greater understanding of the genetic diversity of isolates of Verticillium, is expected to help with development of effective management strategies for Verticillium wilt. The results of this study demonstrate that Verticillium and related species associated with spinach seed display genetic diversity as well as variability in virulence and pathogenicity on spinach and other plant species.

\section{Acknowledgments}

We thank the California Leafy Greens Research Board and the Puget Sound Seed Growers' Association for the support that initiated this project; the American Seed Research Foundation of the American Seed Trade Association for funding for a grant titled 'Epidemiology and Management of Verticillium in Spinach'; and M. Teeter, L. Brissey, and M. Derie for outstanding technical assistance.

\section{Literature Cited}

1. Anonymous. 2003. International Phytosanitary Certificate No. 4051. Phytosanitary Federal Law of the Mexican United States, Phytosanitary Regulation and Inspection Department, Mexico.

2. Anonymous. 2011. United States Department of Agriculture-National Agricultural Statistics Service. http://www.nass.usda.gov

3. Ashworth, L. J., Jr. 1983. Aggressiveness of random and selected isolates of Verticillium dahliae from cotton and the quantitative relationship of internal inoculum to defoliation. Phytopathology 73:1292-1295.

4. Atallah, Z. K., Bae, J., Jansky, S. H., Rouse, D. I., and Stevenson, W. R. 2007. Multiplex real-time quantitative PCR methodology to assist in the breeding of potato lines with resistance to Verticillium wilt. Phytopathology 97:865-872.

5. Atallah, Z. K., Hayes, R. J., and Subbarao, K. V. 2011. Fifteen years of Verticillium wilt of lettuce in America's salad bowl: a tale of immigration, subjugation, and abatement. Plant Dis. 95:784-792.

6. Atallah, Z. K., Maruthachalam, K., du Toit, L. J., Koike, S. T., Davis, R. M., Klosterman, S. J., Hayes, R. J., and Subbarao, K. V. 2010. Population analyses of the vascular plant pathogen Verticillium dahliae detect recombination and transcontinental gene flow. Fungal Genet. Biol. 47:416-422.

7. Atallah, Z. K., Maruthachalam, K., and Subbarao, K. V. 2012. Sources of Verticillium dahliae affecting lettuce. Phytopathology 102:1071-1078.

8. Atallah, Z. K., Maruthachalam, K., Vallad, G. E., Davis, R. M., Klosterman, S. J., and Subbarao, K. V. 2011. Analysis of Verticillium dahliae suggests a lack of correlation between genotypic diversity and virulence phenotypes. Plant Dis. 95:1224-1232.
9. Barbara, D. J., and Clewes, E. 2003. Plant pathogenic Verticillium species: how many of them are there? Mol. Plant Pathol. 4:297-305.

10. Bender, C. G., and Shoemaker, P. B. 1984. Prevalence of Verticillium wilt of tomato and virulence of Verticillium dahliae race 1 and race 2 isolates in western North Carolina. Plant Dis. 68:305-309.

11. Bhat, R. G., Smith, R. F., Koike, S. T., Wu, B. M., and Subbarao, K. V. 2003. Characterization of Verticillium dahliae isolates and wilt epidemics of pepper. Plant Dis. 87:789-797.

12. Bhat, R. G., and Subbarao, K. V. 1999. Host range specificity in Verticillium dahliae. Phytopathology 89:1218-1225.

13. Bidochka, M. L., Leger, R. J. S., Stuart, A., and Gowanlock, K. 1999. Nuclear rDNA phylogeny in the fungal genus Verticillium and its relationship to insect and plant virulence, extracellular proteases and carbohydratases. Microbiology 145:955-963.

14. Chang, R. J., and Eastburn, D. M. 1994. Host range of Verticillium dahliae from horseradish and pathogenicity of strains. Plant Dis. 78:503-506.

15. Collado-Romero, M., Mercado-Blanco, J., Olivares-García, C., and Jiménez-Díaz, R. M. 2008. Phylogenetic analysis of Verticillium dahliae vegetative compatibility groups. Phytopathology 98:1019-1028.

16. Collado-Romero, M., Mercado-Blanco, J., Olivares-García, C., ValverdeCorredor, A., and Jiménez-Díaz, R. M. 2006. Molecular variability within and among Verticillium dahliae vegetative compatibility groups determined by fluorescent amplified fragment length polymorphism and polymerase chain reaction markers. Phytopathology 96:485-495

17. Collins, A., Okoli, C. A. N., Morton, A., Parry, D., Edwards, S. G., and Barbara, D. J. 2003. Isolates of Verticillium dahliae pathogenic to crucifers are of at least three distinct molecular types. Phytopathology 93:364-376.

18. Correll, J. C., Gordon, T. R., and McCain, A. H. 1988. Vegetative compatibility and pathogenicity of Verticillium albo-atrum. Phytopathology 78:1017-1021.

19. Correll, J. C., Gordon, T. R., and McCain, A. H. 1992. Examination of genetic diversity in California and Florida populations of the pitch canker pathogen, Fusarium subglutinans f. sp. pini. Phytopathology 82:415-420.

20. Correll, J. C., Klittich, C. J. R., and Leslie, J. F. 1987. Nitrate nonutilizing mutants of Fusarium oxysporum and their use in vegetative compatibility tests. Phytopathology 77:1640-1646.

21. Correll, J. C., Puhalla, J. E., and Schneider, R. W. 1986. Identification of Fusarium oxysporum f. sp. apii on the basis of colony size, virulence, and vegetative compatibility. Phytopathology 76:396-400.

22. Dobinson, K. F., Harrington, M. A., Omer, M., and Rowe, R. C. 2000 Molecular characterization of vegetative compatibility group 4A and $4 \mathrm{~B}$ isolates of Verticillium dahliae associated with potato early dying. Plant Dis. 84:1241-1245.

23. Dobinson, K. F., Patterson, N. A., White, G. T., and Grant, S. 1998. DNA fingerprinting and vegetative compatibility analysis indicate multiple origins for Verticillium dahliae race 2 tomato isolates from Ontario, Canada. Mycol. Res. 102:1089-1095.

24. Domsch, K. H., Gams, W., and Anderson, T.-H. 1993. Verticillium. Pages 828-845 in: Compendium of Soil Fungi, Vol. 1. IHW-Verlag, Eching, Germany.

25. Douhan, L. I., and Johnson, D. A. 2001. Vegetative compatibility and pathogenicity of Verticillium dahliae from spearmint and peppermint. Plant Dis. 85:297-302.

26. du Toit, L. J., Derie, M. L., Brissey, L. M., and Holmes, B. J. 2010. Evaluation of seed treatments for management of seed borne Verticillium and Stemphylium in spinach, 2009. Plant Dis. Manage. Rep. 4:ST038.

27. du Toit, L. J., Derie, M. L., Brissey, L. M., Holmes, B., and Gatch, E. W. 2009. Evaluation of seed treatments for management of seedborne Verticillium in spinach, 2008. Plant Dis. Manage. Rep. 3:ST020.

28. du Toit, L. J., Derie, M. L, and Hernandez-Perez, P. 2005. Verticillium wilt in spinach seed production. Plant Dis. 89:4-11

29. du Toit, L. J., and Hernandez-Perez, P. 2005. Efficacy of hot water and chlorine for eradication of Cladosporium variabile, Stemphylium botry osum, and Verticillium dahliae from spinach seed. Plant Dis. 89:1305-1312.

30. Duressa, D., Rauscher, G., Koike, S. T., Mou, B., Hayes, R. J., Maruthachalam, K., Subbarao, K. V., and Klosterman, S. J. 2012. A realtime PCR assay for detection and quantification of Verticillium dahliae in spinach seed. Phytopathology 102:443-451.

31. Ebihara, Y., Nagao, H., Uematsu, S., Moriwaki, J., and Kimishima, E. 2003 First report of Verticillium tricorpus isolated from potato tubers in Japan. Mycoscience 44:481-488

32. Friebertshauser, G. E., and DeVay, J. E. 1982. Differential effects of the defoliating and nondefoliating pathotypes of Verticillium dahliae upon the growth and development of Gossypium hirsutum. Phytopathology 72:872877.

33. Horner, C. E. 1954. Pathogenicity of Verticillium isolates to peppermint. Phytopathology 44:239-242.

34. Huisman, O. C. 1988. Seasonal colonization of roots of field-grown cotton by Verticillium dahliae and V. tricorpus. Phytopathology 78:708-716.

35. Inderbitzin, P., Bostock, R. M., Davis, R. M., Usami, T., Platt, H. W., and Subbarao, K. V. 2011. Phylogenetics and taxonomy of the fungal vascular wilt pathogen Verticillium, with the descriptions of five new species. PLoS One 6:28341

36. Isaac, I. 1949. A comparative study of pathogenic isolates of Verticillium. 
Trans. Br. Mycol. Soc. 32:137-157.

37. Isaac, I. 1956. Some soil factors affecting Verticillium wilt of Antirrhinum. Ann. Appl. Biol. 44:105-112.

38. Isaac, I. 1967. Speciation in Verticillium. Annu. Rev. Phytopathol. 5:201222

39. Jiménez-Díaz, R. M., Mercado-Blanco, J., Olivares-García, C., ColladoRomero, M., Bejarano-Alcázar, J., Rodríguez-Jurado, D., Giménez-Jaime, A., García-Jiménez, J., and Armengol, J. 2006. Genetic and virulence diversity in Verticillium dahliae populations infecting artichoke in eastern-central Spain. Phytopathology 96:288-298.

40. Jimenez-Gasco, M., Malcolm, G. M., Berbegal, M., Armengol, J., and Jimenez-Diaz, R. M. 2011. Phylogenetic relationships among Verticillium dahliae vegetative compatibility groups based on IGS and polymorphic sequences. (Abstr.) Phytopathology 101:S83.

41. Joaquim, T. R., and Rowe, R. C. 1990. Reassessment of vegetative compatibility relationships among strains of Verticillium dahliae using nitrate-nonutilizing mutants. Phytopathology 80:1160-1166.

42. Joaquim, T. R., and Rowe, R. C. 1991. Vegetative compatibility and virulence of strains of Verticillium dahliae from soil and potato plants. Phytopathology 81:552-558.

43. Klosterman, S. J., Atallah, Z. K., Vallad, G. E., and Subbarao, K. 2009. Diversity, pathogenicity, and management of Verticillium species. Annu. Rev. Phytopathol. 47:39-62.

44. Klosterman, S. J., and Hayes, R. J. 2009. A soilless Verticillium wilt assay using an early flowering lettuce line. Plant Dis. 93:691-698.

45. Koike, M., Fujita, M., Nagao, H., and Ohshima, S. 1996. Random amplified polymorphic DNA analysis of Japanese isolates of Verticillium dahliae and V. albo-atrum. Plant Dis. 80:1224-1227.

46. Korolev, N., Katan, J., and Katan, T. 2000. Vegetative compatibility groups of Verticillium dahliae in Israel. Their distribution and association with pathogenicity. Phytopathology 90:529-536.

47. Larkin, M. A., Blackshields, G., Brown N. P., Chenna, R., McGettigan, P. A., McWilliam, H., Valentin, F., Wallace, I. M., Wilm, A., Lopez, R., Thompson, J. D., Gibson, T. J., and Higgins, D. G. 2007. Clustal W and Clustal X version 2.0. Bioinformatics 23:2947-2948.

48. Leslie, J. F. 1993. Fungal vegetative compatibility. Annu. Rev. Phytopathol. 31:127-150.

49. Maruthachalam, K., Atallah, Z. K., Vallad, G. E., Klosterman, S. J., Hayes, R. J., Davis, R. M., and Subbarao, K. V. 2010. Molecular variation among isolates of Verticillium dahliae and polymerase chain reaction-based differentiation of races. Phytopathology 100:1222-1230.

50. McMoran, D. 2010. Skagit County Agricultural Statistics. Skagit County Extension, Washington State University. http://skagit.wsu.edu/agriculture/ index.htm

51. Melouk, H. A., and Horner, C. E. 1974. Verticillium nigrescens from peppermint. Phytopathology 64:1267-1268.

52. Messner, R., Schweigkofler, W., Schweigkofler, M., Berg, G., and Prillinger, H. 1996. Molecular characterization of the plant pathogen Verticillium dahliae Kleb. using RAPD-PCR and sequencing of the 18S rRNA gene. J. Phytopathol. 144:347-354.

53. Morton, A., Carder, J. H., and Barbara, D. J. 1995. Sequences of the internal transcribed spacers of the ribosomal RNA genes and relationships between isolates of Verticillium alboatrum and V. dahliae. Plant Pathol. 44:183-190.

54. Morton, A., Tabrett, A. M., Carder, J. H., and Barbara, D. J. 1995. Subrepeat sequences in the ribosomal RNA intergenic regions of Verticillium alboatrum and V. dahliae. Mycol. Res. 99:257-266.

55. Okoli, C. A. N, Carder, J. H., and Barbara, D. J. 1994. Restriction fragment length polymorphisms (RFLPs) and the relationships of some host-adapted isolates of Verticillium dahliae. Plant Pathol. 43:33-40.

56. Pantou, M. P., Strunnikova, O. K., Shakhnazarova, V. Y., Vishnevskaya, N. A., Papalouka, V. G., and Typas, M. A. 2005. Molecular and immunochemical phylogeny of Verticillium species. Mycol. Res. 109:889-902.

57. Pegg, G. F., and Brady, B. L. 2002. Verticillium Wilts. CABI Publishing, Oxford.

58. Perez-Artes, E., Garcia-Pedrajas, M. D., Bejarano-Alcazar, J., and JimenezDiaz, R. M. 2000. Differentiation of cotton-defoliating and nondefoliating pathotypes of Verticillium dahliae by RAPD and specific PCR analyses. Eur. J. Plant Pathol. 106:507-517.

59. Puhalla, J. E., and Hummel, M. 1983. Vegetative compatibility groups within Verticillium dahliae. Phytopathology 73:1305-1308.

60. Qin, Q. M., Vallad, G. E., and Subbarao, K. V. 2008. Characterization of Verticillium dahliae and V. tricorpus isolates from lettuce and artichoke. Plant Dis. 92:69-77.
61. Qin, Q. M., Vallad, G. E., Wu, B. M, and Subbarao, K. V. 2006. Phylogenetic analyses of phytopathogenic isolates of Verticillium spp. Phytopathology 96:582-592.

62. Resende, M. L. V., Flood, J., and Cooper, R. M. 1994. Host specialization of Verticillium dahliae, with emphasis on isolates from cocoa (Theobroma cacao). Plant Pathol. 43:104-111.

63. Rowe, R. C. 1995. Recent progress in understanding relationships between Verticillium species and subspecific groups. Phytoparasitica 23:31-38.

64. Sackston, W. E., and Sedun, F. S. 1982. Verticillium wilt of spinach: A useful experimental system. Can. J. Plant Pathol. 4:310.

65. Skotland, C. B. 1971. Pathogenic and nonpathogenic Verticillium species from south central Washington. Phytopathology 61:434-436.

66. Snyder, W. C., and Wilhelm, S. 1962. Seed transmission of Verticillium wilt of spinach. (Abstr.) Phytopathology 52:365.

67. Sorensen, L. H., Schneider, A. T., and Davis, J. R. 1991. Influence of sodium polygalacturonate sources and improved recovery of Verticillium spp. from soil. Phytopathology 81:1347.

68. Strausbaugh, C. A. 1993. Assessment of vegetative compatibility and virulence of Verticillium dahliae isolates from Idaho potatoes and tester strains. Phytopathology 83:1253-1258.

69. Strausbaugh, C. A., Schroth, M. N., Weinhold, A. R., and Hancock, J. G. 1992. Assessment of vegetative compatibility of Verticillium dahliae tester strains and isolates from California potatoes. Phytopathology 82:61-68.

70. Subbarao, K. V., Chassot, A., Gordon, T. R., Hubbard, J. C., Bonello, P. Mullin, R., Okamoto, D., Davis, R. M., and Koike, S. T. 1995. Genetic relationships and cross pathogenicities of Verticillium dahliae isolates from cauliflower and other crops. Phytopathology 85:1105-1112.

71. Tamura, K., Dudley, J., Nei, M., and Kumar, S. 2007. MEGA4: molecular evolutionary genetics analysis (MEGA) software version 4.0. Mol. Biol. Evol. 24:1596-1599.

72. Taylor, J. B. 1969. Host specificity of Verticillium dahliae to tobacco. N.Z. J. Sci. 12:709-712.

73. Tveden-Nyborg, S. 2008. Det Regionale Teknologicenter Seedland, Aarhus Universitet. http://www.seedland.dk

74. Usami, T., Kanto, T., Inderbitzin, P., Itoh, M., Kisaki, G., Ebihara, Y., Suda, W., Amemiya, Y., and Subbarao, K. V. 2011. Verticillium tricorpus causing lettuce wilt in Japan differs genetically from California lettuce isolates. J. Gen. Plant Pathol. 77:17-23.

75. Uys, M. D. R., Rong, I. H., and Holz, G. 1997. Verticillium tricorpus associated with wilt of tomato in South Africa. Afr. Plant Prot. 3:73-75.

76. Vallad, G. E., Qin, Q. M., Grube, R., Hayes, R. J., and Subbarao, K. V. 2006. Characterization of race-specific interactions among isolates of Verticillium dahliae pathogenic on lettuce. Phytopathology 96:1380-1387.

77. Vallad, G. E., and Subbarao, K. V. 2008. Colonization of resistant and susceptible lettuce cultivars by a green fluorescent protein-tagged isolate of Verticillium dahliae. Phytopathology 98:871-885.

78. van der Spek, J. 1972. Internal carriage of Verticillium dahliae by seeds and its consequence. Meded. Fac. Landbouwwet. Rijksuniv. Gent. 37:567573.

79. van der Spek, J. 1973. Seed transmission of Verticillium dahliae. Meded. Fac. Landbouwwet. Rijksuniv. Gent. 38:1427-1434.

80. Vesper, S. J., Turner, J. T., Jr., and Phillips, D. V. 1983. Incidence of Verticillium nigrescens in soybeans. Phytopathology 73:1338-1341.

81. Villarroel-Zeballos, M. I. 2007. Genetic, molecular, and virulence diversity of Verticillium dahliae and screening for disease resistance in spinach germplasm. M.S. thesis, University of Arkansas, Fayetteville.

82. Villarroel-Zeballos, M. I., Feng, C., Iglesias, A., du Toit, L. J., and Correll, J. C. 2012. Screening for resistance to Verticillium wilt in spinach and isolation of Verticillium dahliae from seed of spinach accessions. HortScience 47:1297-1303.

83. White, T. J., Bruns, T., Lee, S., and Taylor, J. 1990. Amplification and direct sequencing of fungal ribosomal RNA genes for phylogenetics. Pages 315 322 in: PCR Protocols. M. A. Innes, D. H. Gelfand, J. S. Sninsky, and T. J. White, eds. Academic Press, London.

84. Wiese, M. V., DeVay, J. E., and Ravenscroft, A. V. 1970. Relationship between polygalacturonase activity and cultural characteristics of Verticillium isolates pathogenic in cotton. Phytopathology 60:641-646.

85. Zare, R., Gams, W., Starink-Willemse, M., and Summerbell, R. C. 2007 Gibellulopsis, a suitable genus for Verticillium nigrescens, and Musicillium, a new genus for $V$. theobromae. Nova Hedwigia 85:463-489.

86. Zeise, K., and von Tiedemann, A. 2002. Host specialization among vegetative compatibility groups of Verticillium dahliae in relation to Verticillium longisporum. J. Phytopathol. 150:112-119. 